\title{
Cones Respond to Light in the Absence of Transducin $\beta$ Subunit
}

\author{
Sergei S. Nikonov, ${ }^{1}$ Arkady Lyubarsky, ${ }^{2}$ Marie E. Fina, ${ }^{1}$ Elena S. Nikonova, ${ }^{1}$ Abhishek Sengupta, ${ }^{1}$ \\ Chidambaram Chinniah, ${ }^{1}$ Xi-Qin Ding, ${ }^{3}$ Robert G. Smith, ${ }^{1}$ Edward N. Pugh Jr, ${ }^{4}$ Noga Vardi, ${ }^{1}$ and Anuradha Dhingra ${ }^{1}$ \\ Departments of ${ }^{1}$ Neuroscience and ${ }^{2}$ Ophthalmology, University of Pennsylvania, Philadelphia, Pennsylvania, 19104, ${ }^{3}$ Department of Cell Biology, \\ University of Oklahoma Health Sciences Center, Oklahoma City, Oklahoma 73104, and ${ }^{4}$ Department of Physiology and Membrane Biology, University of \\ California, Davis, Davis, California 95618
}

Mammalian cones respond to light by closing a cGMP-gated channel via a cascade that includes a heterotrimeric G-protein, cone transducin, comprising $\mathrm{G} \alpha \mathrm{t} 2, \mathrm{G} \beta 3$ and $\mathrm{G} \gamma \mathrm{t} 2$ subunits. The function of $\mathrm{G} \beta \gamma$ in this cascade has not been examined. Here, we investigate the role of $\mathrm{G} \beta 3$ by assessing cone structure and function in $\mathrm{G} \beta 3$-null mouse $\left(\mathrm{Gnb} 3^{-1-}\right)$. We found that $\mathrm{G} \beta 3$ is required for the normal expression of its partners, because in the $G n b 3^{-1-}$ cone outer segments, the levels of $\mathrm{G} \alpha \mathrm{t} 2$ and $\mathrm{G} \gamma \mathrm{t} 2$ are reduced by fourfold to sixfold, whereas other components of the cascade remain unaltered. Surprisingly, Gnb3 ${ }^{-1-}$ cones produce stable responses with normal kinetics and saturating response amplitudes similar to that of the wild-type, suggesting that cone phototransduction can function efficiently without a $\mathrm{G} \beta$ subunit. However, light sensitivity was reduced by approximately fourfold in the knock-out cones. Because the reduction in sensitivity was similar in magnitude to the reduction in $\mathrm{G} \alpha \mathrm{t} 2$ level in the cone outer segment, we conclude that activation of $\mathrm{G} \alpha \mathrm{t} 2$ in $\mathrm{Gnb3}^{-I-}$ cones proceeds at a rate approximately proportional to its outer segment concentration, and that activation of phosphodiesterase and downstream cascade components is normal. These results suggest that the main role of $\mathrm{G} \beta 3$ in cones is to establish optimal levels of transducin heteromer in the outer segment, thereby indirectly contributing to robust response properties.

\section{Introduction}

Heterotrimer G-proteins are central to many neural signaling pathways and serve to amplify the signal. These heterotrimers mediate diverse processes, such as vision, olfaction, taste, muscle contraction and relaxation, heart rate, and a variety of other neuronal activities. In mammals, there are 16 types of $\alpha$ subunit, 4 conventional $\beta$ subunits, and $12 \gamma$ subunits (Larhammar et al., 2009). Different combinations of these subunits associate to form different heterotrimeric complexes. A well recognized prototype of a G-protein cascade is mammalian phototransduction.

Light absorbed by rhodopsin and cone opsins activates the G-protein transducin. The GTP-bound form of $\alpha$ transducin dissociates from $\mathrm{G} \beta \gamma$ and activates phosphodiesterase (PDE), which in turn reduces cytosolic cGMP concentration. This results in the closure of the photoreceptor's cGMP-gated channels and cells' hyperpolarization. The cascade is terminated by hydrolysis of

\footnotetext{
Received Nov. 7, 2012; revised Jan. 11, 2013; accepted Feb. 5, 2013.

Author contributions:S.S.N., A.L., N.V., and A.D. designed research;S.S.N., A.L., M.E.F., E.S.N., A.S., C.C., and A.D. performed research;S.S.N., A.L., X.-Q.D., N.V., and A.D. contributed unpublished reagents/analytic tools; S.S.N., A.L., M.E.F., E.S.N., A.S., C.C., R.G.S., E.N.P., N.V., and A.D. analyzed data; S.S.N., A.L., R.G.S., E.N.P., N.V., and A.D. wrote the paper.

This work was supported by National Institutes of Health Grants EY11105 (N.V.); R21 EY021308 (N.V. and R.G.S.); NEI P30 EY01583 (Vision Research Core of the University of Pennsylvania); and EY02660 (E.N.P.). We thank Drs. Ágoston Szel, Theodore Wensel, Vadim Arshavsky, Cheryl Craft, and Virginia Lee for donating the antibodies used in this study.

The authors declare no competing financial interests.

Correspondence should be addressed to Sergei S. Nikonov, 123 Anat-Chem Building, Philadelphia, PA 191046058. E-mail: sergein@mail.med.upenn.edu.

DOI:10.1523/JNEUROSCI.5204-12.2013

Copyright $\odot 2013$ the authors $\quad 0270-6474 / 13 / 335182-13 \$ 15.00 / 0$
}

GTP, which is accelerated by the GTPase-activating protein (GAP) complex. This molecular complex comprises a regulator of the G-protein signaling protein RGS9, a distant member of $\mathrm{G} \beta$, $\mathrm{G} \beta 5$, and a membrane anchor protein R9AP (reviewed by Slepak, 2009; Burns and Pugh, 2010).

Rods and cones share similar molecular mechanisms for phototransduction that are optimized differently to impart specific functional properties to these cells. Rods have higher light sensitivity with photoresponses that saturate in bright light; cones have lower sensitivity, faster responses, and more efficient light adaptation over a broad range of backgrounds. Mammalian rods and cones use different G-protein heterotrimers: rods use $\mathrm{G} \alpha \mathrm{t} 1 \beta 1 \gamma 1$ and cones G $\alpha \mathrm{t} 2 \beta 3 \gamma \mathrm{t} 2$ (Lerea et al., 1986; Lee et al., 1992; Peng et al., 1992; Ong et al., 1995; Larhammar et al., 2009). The $\mathrm{G} \alpha$ subunits of rods and cones have been shown to be functionally interchangeable in transfected systems and in vitro, but the identity of the transducin $\alpha$ subunit shapes the unique physiological properties of rods and cones (Deng et al., 2009; Chen et al., 2010; Gopalakrishna et al., 2012). Elimination of G $\alpha \mathrm{t} 1$ abolishes rod-driven responses, and similarly, mutations in G $\alpha \mathrm{t} 2$ abolish photopic responses and cause achromatopsia in human (Calvert et al., 2000; Chang et al., 2006). In contrast, deleting rod G $\gamma 1$ did not eliminate light responses, although the sensitivity was much reduced (Lobanova et al., 2010; Kolesnikov et al., 2011). These studies raised the possibility that the photoreceptors can function with $\mathrm{G} \alpha$ monomer, although the investigators favored the alternate explanation that another $\mathrm{G} \gamma$ subunit forms the heterotrimer in the outer segments. This question should be easier to address by eliminating $\mathrm{G} \beta$ because only 4 isoforms of 
Table 1. Antibodies used

\begin{tabular}{|c|c|c|}
\hline Antibody & Dilution & Source/reference \\
\hline Ms anti-Blue opsin & $1: 50$ & Dr. Ágoston Szél, Semmelweis University, Budapest, Hungary \\
\hline Ms anti-Red/green opsin & $1: 50$ & Dr. Ágoston Szél, Semmelweis University, Budapest, Hungary \\
\hline Rb anti-Blue opsin & $1: 1000(1: 1500)$ & Millipore \\
\hline Rb anti-Red/green opsin & $1: 1000(1: 1500)$ & Millipore \\
\hline $\mathrm{Rb}$ anti-G $\beta \beta 3$ & $1: 300$ & HPA005645, Sigma \\
\hline $\mathrm{Rb}$ anti-G $\alpha \mathrm{t} 2$ & $1: 1000(1000)$ & Dr. Vadim Arshavsky, Duke University, Durham, NC \\
\hline Rb anti-G $\gamma t 2$ & $1: 750$ & Dr. Vadim Arshavsky, Duke University, Durham, NC \\
\hline $\mathrm{Rb}$ anti-G $\beta 5$ & $1: 500$ & Dr. Theodore Wensel, Baylor College of Medicine, Houston, TX \\
\hline $\mathrm{Rb}$ anti-G $\beta 1$ & $1: 50$ & SC-379, Santa Cruz Biotechnology \\
\hline $\mathrm{Rb}$ anti-CNGA3 & $1: 250(1: 500)$ & (Ding et al., 2008; Matveev et al., 2008) \\
\hline Rb anti-CNGB3 & $1: 250$ & (Ding et al., 2008; Matveev et al., 2008) \\
\hline Rb anti-R9AP & $1: 1,000$ & Dr. Vadim Arshavsky, Duke University, Durham, NC \\
\hline $\mathrm{Rb}$ anti-Cone-arrestin & $1: 500$ & Dr. Cheryl Craft, University of Southern California, Los Angeles, CA \\
\hline Rb anti-Vimentin & $1: 2000$ & Dr. Virginia Lee, University of Pennsylvania, Philadelphia, PA \\
\hline Rb anti-Glutamine synthase & $1: 200$ & BD BioScience \\
\hline Ms anti- $\beta$ actin & $(1: 3000)$ & Clone AC-74 Sigma \\
\hline
\end{tabular}

Sources of the used antibodies along with the corresponding dilutions for immunocytochemistry and Western blotting (in parentheses). Ms, Mouse; Rb, rabbit.

conventional G $\beta$ subunits exist. Here we show that the expression levels of $\mathrm{G} \alpha$ and $\mathrm{G} \gamma$ subunits in cones lacking $\mathrm{G} \beta 3$ are reduced relative to the wild-type (WT) with no detectable expression of any conventional G $\beta$ subunit. Yet, the amplitudes of the saturating light responses are very similar to those in the WT, albeit with lower sensitivity. Interestingly, response amplification and sensitivity correlate with the amount of remaining $\mathrm{G} \alpha$ subunit, suggesting that the role of the G-protein $\beta$ subunit in the light response is mainly indirect, i.e., to help traffic and assemble the G-protein complex in the outer segment.

\section{Materials and Methods}

Mouse genotypes and tissue preparation. The generation and characterization of $\mathrm{Gnb3}^{-1-}$ and Grm6-GFP mice was previously described (Morgan et al., 2006; Dhingra et al., 2008, 2012). WT C57BL/6J mice were purchased from Charles River Laboratories. Most experiments used 3- to 8 -week-old male and female mice. Some immunostainings were performed on retinas from older mice ( 5 months for R9AP and 7 months for CNGB3) and the results were similar to those in the younger animals. Mice were treated in compliance with Federal regulations and University of Pennsylvania policy. Mice were deeply anesthetized by intraperitoneal injection of a mixture of ketamine $(100 \mu \mathrm{g} / \mathrm{g})$ and xylazine $(10 \mu \mathrm{g} / \mathrm{g})$, the eyes were enucleated and the mouse was killed by anesthetic overdose.

Immunocytochemistry. After enucleation, a small cut was made at the ora serrata. The eyeball was fixed in $4 \%$ paraformaldehyde for 10 or 60 min; rinsed in phosphate buffer; soaked overnight in $30 \%$ buffered sucrose; and embedded in a mixture of two parts $20 \%$ sucrose in phosphate buffer and one part tissue-freezing medium. The eye was cryosectioned radially at $10-15 \mu \mathrm{m}$ thickness. Sections were soaked in diluent containing $10 \%$ normal goat serum, $5 \%$ sucrose, and $0.5 \%$ Triton X-100 in phosphate buffer. These sections were then incubated in primary antibodies (Table 1) at $4^{\circ} \mathrm{C}$ overnight; washed; incubated for $3 \mathrm{~h}$ in secondary antibodies conjugated to a fluorescent marker; rinsed; and mounted in Vectashield (Vector Laboratories). In some experiments, fluorescein conjugated peanut agglutinin (PNA; 1:1000, Vector Laboratories) was included in the primary antibody incubation step. Unlike in rods, transducin in cones does not translocate under normal daylight conditions, therefore in these experiments the state of dark-adaptation was not considered relevant (Lobanova et al., 2010).

Imaging and quantification. Detailed quantification methods have been described previously (Xu et al., 2012). Briefly, sections were photographed with an Olympus FV-1000 confocal microscope with a $40 \times$ or $60 \times$ oil-immersion objective. Immunostaining intensities were compared between a set of age-matched WT and null retinas that were simultaneously processed and imaged under the same settings. Intensity measurements were taken from $z$-stacks ( $1 \mu \mathrm{m}$ apart; same number of sections for WT and null mice) using Volocity software (Improvision). Regions of interest (ROI) were drawn for the cone outer segment (OS), and in some cases for the OS and the rest of the cell (inner segment, axon, and cone terminal) and total intensity in each ROI was measured. Intensity values were adjusted to account for the mean background intensity level (measured from the inner nuclear layer). Average intensity across 10-20 ROIs was used to determine the ratio of null to WT for each set. For each parameter, ratios from at least three sets were obtained and two-tailed one sample $t$ test was used to check whether the sample mean ratio was different from 1.

Western blotting and quantification. Retinas from $\mathrm{Gnb3}^{-1-}$ and WT littermate mice were detached quickly from anesthetized mice and frozen in liquid nitrogen. Tissue was homogenized using a Polytron homogenizer in a lysis buffer containing $5 \mathrm{~mm}$ Tris- $\mathrm{HCl}, \mathrm{pH} 7.5,320 \mathrm{~mm}$ sucrose, 2 mм EDTA, 2.5 mм 2-mercaptoethanol, and protease inhibitor mixture (P 8340, Sigma). The homogenate was centrifuged for $10 \mathrm{~min}$ at $6000 \times$ $\mathrm{g}$ (for most experiments) or $20,000 \times \mathrm{g}$ (in 3 sets of retinas to obtain a clearer supernatant for $\mathrm{G} \alpha \mathrm{t} 2$ quantification). The two procedures yielded similar results; therefore, all sets of data were combined for the final analysis. Proteins from the supernatant were assayed using BSA protein reagent (Bio-Rad). The proteins for the $G n b 3^{-/-}$and WT littermate control were run on 4-15\% SDS-PAGE gels and transferred to a nitrocellulose membrane using a wet transfer apparatus (Bio-Rad). After a brief rinse in PBS, the blots were incubated sequentially in the following: Odyssey blocking buffer diluted with PBS (1:1, blocking buffer) at room temperature for $1 \mathrm{~h}$; primary antibody (Table 1) diluted in blocking buffer containing $0.1 \%$ Tween 20 at $4^{\circ} \mathrm{C}$ overnight; washes in PBS $+0.1 \%$ Tween 20 (PBST); IRDye-conjugated secondary antibodies (from LI-COR Biosciences or Rockland, 1:15,000 dilution in blocking buffer containing $0.1 \%$ Tween 20 ) at room temperature for $1 \mathrm{~h}$; washes in PBST; and a final rinse in PBS. The blots were then scanned using the Odyssey Infrared Imaging system (LI-COR Biosciences) according to the manufacturer's instructions. To control for equal loading, antibody against an internal control protein ( $\beta$-actin) was also included along with test antibody. The two antibodies used together were chosen such that they differed in the host species to enable their discrimination by different secondary antibodies. The band intensities were quantified using Odyssey software, adjusted for background and normalized against $\beta$-actin levels. Two-tailed paired $t$ test was used to test statistical significance between the WT and null protein levels.

The level of G $\alpha \mathrm{t} 2$ in the OS of the null mouse relative to that of the WT was also calculated by an alternate approach combining the Western blot and immunocytochemistry data. We reasoned that G $\alpha \mathrm{t} 2$ levels in the OS as a fraction of total cone levels obtained by immunocytochemistry would be a representative estimate of the protein distribution within the WT and null cones. We therefore used this ratio to obtain the relative 
fraction in OS from total G $\alpha \mathrm{t} 2$ as obtained from Western blotting as detailed below.

Let $\mathrm{G} \alpha \mathrm{t} 2$ distribution be: $\mathrm{D}_{\mathrm{KO}}=\mathrm{OS}_{\mathrm{KO}} / \mathrm{CONE}_{\mathrm{KO}}$ and $\mathrm{D}_{\mathrm{WT}}=\mathrm{OS}_{\mathrm{WT}} /$ $\mathrm{CONE}_{\mathrm{WT}}$, where $\mathrm{OS}_{\mathrm{KO}}$ and $\mathrm{OS}_{\mathrm{WT}}$ are levels of $\mathrm{G} \alpha \mathrm{t} 2$ in the cone outer segment and $\mathrm{CONE}_{\mathrm{KO}}$ and $\mathrm{CONE}_{\mathrm{WT}}$ are the levels in the cones for $\mathrm{KO}$ and WT retina. $\mathrm{D}_{\mathrm{KO}}$ and $\mathrm{D}_{\mathrm{WT}}$ are therefore the fractions of $\mathrm{G} \alpha \mathrm{t} 2$ in cone OS relative to that in the cone cell, and these are measured by immunocytochemistry.

Taking the ratio of $\mathrm{D}_{\mathrm{KO}}$ and $\mathrm{D}_{\mathrm{WT}}$ and rearranging, we get:

$$
\mathrm{OS}_{\mathrm{KO}} / \mathrm{OS}_{\mathrm{WT}}=\left(\mathrm{D}_{\mathrm{KO}} / \mathrm{D}_{\mathrm{WT}}\right)\left(\mathrm{CONE}_{\mathrm{WT}} / \mathrm{CONE}_{\mathrm{KO}}\right) \text {. }
$$

Assuming that $\mathrm{CONE}_{\mathrm{KO}} / \mathrm{CONE}_{\mathrm{WT}}$ obtained by Western blot is more reliable than that obtained by immunocytochemistry, this provides an alternate estimate for $\mathrm{OS}_{\mathrm{KO}} / \mathrm{OS}_{\mathrm{WT}}$.

Electroretinographic recordings. The electroretinographic (ERG) recording methods were described previously in detail (Lyubarsky et al., 1999, 2000; Ng et al., 2010). Briefly, an adult mouse was dark-adapted overnight, then anesthetized under dim red light by intraperitoneal injection of a mixture containing ( $\mathrm{mg} / \mathrm{g}$ body weight) 20 ketamine, 8 xylazine, and 800 urethane, and placed onto a platform maintained at $38^{\circ} \mathrm{C}$. The pupils were dilated with $1 \%$ tropicamide saline solution (Mydriacyl, Alconox). A platinum recording electrode was placed in contact with the cornea, and another platinum wire electrode placed into the mouth was used as both reference and ground electrode. The platform with the mouse was then partially moved into a Ganzfeld (Espion Electrophysiology System, Diagnosys) in a position ensuring an isotropic uniform illumination of the mouse head. The Ganzfeld and the platform with the animal were enclosed by a lightproof aluminum grounded Faraday cage. The light stimuli were either $4 \mathrm{~ms}$ flashes produced by an LED stimulator or $<1 \mathrm{~ms}$ flashes produced by a Xenon tube delivered in the Ganzfeld. ERGs were recorded from both eyes with a bandwidth of $0.1-1 \mathrm{kHz}$, and were sampled at $1 \mathrm{~ms}$ intervals. A typical record was an average of 3-25 individual responses (depending on the signal/noise ratio). Light intensities were converted to estimated number of photons per $\mu \mathrm{m}^{2}$ at the cornea as previously described (Lyubarsky et al., 1999).

Determination of the flicker response magnitude and sensitivity. At the beginning of the experiment the mouse was adapted to a green $\left(\lambda_{\max }=\right.$ $513 \mathrm{~nm}$ ) light of $30 \mathrm{scot} \mathrm{cd} \mathrm{m}^{-2}$ intensity for $5 \mathrm{~s}$. This background illumination was maintained for the whole duration of stimulation. Flash flicker $(10 \mathrm{~Hz}, 1-4 \mathrm{~ms}$; depending on intensity) was delivered as sequences of 20 to 50 1-s-long trials for each stimulus intensity. The trial responses were averaged and saved. The data file was exported and processed with a custom interactive Matlab (Mathworks) program that performed averaging of responses, determined peak-to trough amplitude of mean responses, and gave an intensity-response plot in a log-log scale. The range of intensities corresponding to an approximately linear intensity-response relation was identified by visual inspection of the respective plot, and a least square linear fit to the data points was performed using the Matlab program. The ratio of response amplitude to stimulus intensity in this linear range (i.e., the slope of a linear part of the intensityresponse relation corresponding to the dimmest stimuli) was defined as the "flicker response sensitivity."

Spectral sensitivity as a measure of preservation of both $S$ and $L / M$ pigment-mediated cone function. As a measure of the preservation of both $\mathrm{S}$ and $\mathrm{L} / \mathrm{M}$ pigment mediated inputs, we chose the ERG response to a 10 $\mathrm{Hz}$ flash-flicker stimulus delivered on a $30 \mathrm{~cd} \mathrm{~m}^{-2}$ rod-suppressing background. We chose flicker ERG over single-flash ERG because the magnitude of single flash ERG under rod-saturating background in $\mathrm{Gnb3}^{-1-}$ mice was much lower than in WT animals, and reliable measurements of its amplitude required averaging of hundreds of individual responses. We chose a slow $10 \mathrm{~Hz}$ flicker over commonly used $30 \mathrm{~Hz}$ flicker, because in the course of preliminary experiments with WT mice we found that the temporal response function (flicker response amplitude vs flicker frequency) fell with increase in frequency faster for the $\lambda=$ $365 \mathrm{~nm}$ stimulation than for the $\lambda=513 \mathrm{~nm}$ stimulus. Thus, a $10 \mathrm{~Hz}$ stimulus gave a more constant UV/green ratio, which reflected the actual relative contents of the $\mathrm{S}$ and $\mathrm{M} / \mathrm{L}$ cone pigments and functionality of respective pathways.
Suction pipette recording. Suction pipette recording from WT and KO mouse cones were performed according to the previously published procedures (Nikonov et al., 2006). Briefly, mice were intraperitoneally injected with a lethal dose of ketamine/xylazine mixture (100 $\mu \mathrm{g} / \mathrm{g}$ ketamine and $10 \mu \mathrm{g} / \mathrm{g}$ xylazine) under dim red light and eyes were dissected under infrared light. To preserve retinal orientation during dissection, a small mark was made on the ventral part of the cornea using high temperature cautery (World Precision Instruments). The eyes were quickly enucleated, trimmed from muscles, and attached with a small drop of cyanoacrylate glue to a dry Petri dish. A mark was scratched on the bottom of a Petri dish corresponding to the mark on the cornea and the dish was filled with Locke's solution $(112.5 \mathrm{~mm} \mathrm{NaCl}, 3.6 \mathrm{mM} \mathrm{KCl}, 2.4$ $\mathrm{mm} \mathrm{MgCl}_{2}, 1.2 \mathrm{~mm} \mathrm{CaCl}_{2}, 10 \mathrm{~mm}$ HEPES, $0.02 \mathrm{~mm}$ EDTA, $20 \mathrm{~mm}$ $\mathrm{NaHCO}_{3}, 3 \mathrm{~mm} \mathrm{Na}_{2}$-succinate, $0.5 \mathrm{~mm}$ Na-glutamate, $10 \mathrm{~mm}$ glucose) also containing bovine serum albumin (BSA; $0.1 \mathrm{mg} / \mathrm{ml}$ ). A small piece from the extreme dorsal region of the retina was excised, sliced, and transferred to the recording chamber. The chamber was perfused with Locke's solution ( $\mathrm{pH} 7.4$, no BSA added) and maintained at $35-37^{\circ} \mathrm{C}$ with a heating system designed for microscopy (Warner Instruments). The Locke's solution was continuously bubbled with a gas mixture containing $95 \% \mathrm{O}_{2} / 5 \% \mathrm{CO}_{2}$ before it was directed into the chamber.

Freshly pulled glass pipettes with a tip internal diameter of $\sim 3 \mu \mathrm{m}$ were used for the "outer segment out" cone recording. The pipette, pipette holder, and a tube connecting pipette holder to the pressure control system were filled with Locke's solution. A small air bubble separated Locke's solution from the oil-filled pressure control system. After drawing a few nuclei and conjoined inner segments into the pipette, the rod currents were suppressed for $3 \mathrm{~s}$ by the background light $(500 \mathrm{~nm}, 20,000$ photons $\left.\mu \mathrm{m}^{-2} \mathrm{~s}^{-1}\right)$. The background was selected to be bright enough to suppress all measurable rod activity but dim enough $(\sim 1 / 7$ of half saturating intensity for M-cones) (Nikonov et al., 2006) to have negligible effect on $\mathrm{M}$-cone properties. Cone responses were tested by delivering a bright saturating flash $(500 \mathrm{~nm}, 5 \mathrm{~ms}$ duration, from 377,000 to 758,000 photons $\mu \mathrm{m}^{-2}$ depending on the genotype) superimposed on the background light $0.75 \mathrm{~s}$ after background onset. After observation of a robust cone response, a recording was started by repeating the above stimulation pattern with flash intensities varying from 1820 to 2,920,000 photons $\mu \mathrm{m}^{-2}$ (up to 75 repetitions for each of the dim flash intensities, $\sim 12$ repetitions for the saturating flash intensities). Flashes of the same intensity were repeated at the beginning and at the end of the experiment to monitor for the response stability. Data collection and light stimulation were done with PC-505B patch-clamp amplifier (Warner Instruments), Axon Digidata 1400 digitizer, and Clampex software (Molecular Devices). All responses were low-pass filtered at $30 \mathrm{~Hz}$ before data storage. Tektronix TDS2014C digital oscilloscope was used for online observation and averaging of the responses during the experiments. In a number of experiments ( 22 of 33 total cone recordings), a control series of rod flash and step response (flash intensities ranging from 7 to 2680 photons $\mu \mathrm{m}^{-2}$, step intensities ranging from 7 to 27,900 photons $\mu \mathrm{m}^{-2} \mathrm{~s}^{-1}$ ) was obtained from the slice before cone recording was commenced. In every control record, the measured rod parameters were in good agreement with the previously published results, and rod currents were undetectable on a background of 20,000 photons $\mu \mathrm{m}^{-2} \mathrm{~s}^{-1}$.

Light stimulation and light calibration. For light stimulation we used Osram $528 \mathrm{~nm}$ LED fitted with $500 \mathrm{~nm}$ interference filter $(10 \mathrm{~nm}$ FWHM, Edmund Optics), driven by a custom-designed circuit under the control of Clampex software. The light intensities were measured in the recording chamber with a calibrated photodiode (OSI Optoelectronics). The illuminated area was imaged with an Olympus Fluoview confocal system and analyzed for illumination uniformity. Measured light intensities were divided by the illuminated area and multiplied by the flash duration $(5 \mathrm{~ms})$ to give flash intensities in photons $\mu \mathrm{m}^{-2}$. The cone collecting area $\mathrm{a}_{\mathrm{c}}$ was calculated as previously described (Nikonov et al., $2005,2006)$ as $0.2 \mu \mathrm{m}^{2}$ for a $500 \mathrm{~nm}$ light.

Mouse cones from the dorsal retina are known to contain mainly medium wavelength-sensitive pigment (M-pigment, sensitivity peak at $\sim 508 \mathrm{~nm}$ ). Any coexpression of UV-sensitive pigment (S-pigment, sensitivity peak at $361 \mathrm{~nm}$ ) had minimal effect on our results, because: (1) $\mathrm{S}$-pigment is $\sim 5 \log$ units less sensitive at $500 \mathrm{~nm}$ compared with the 
A
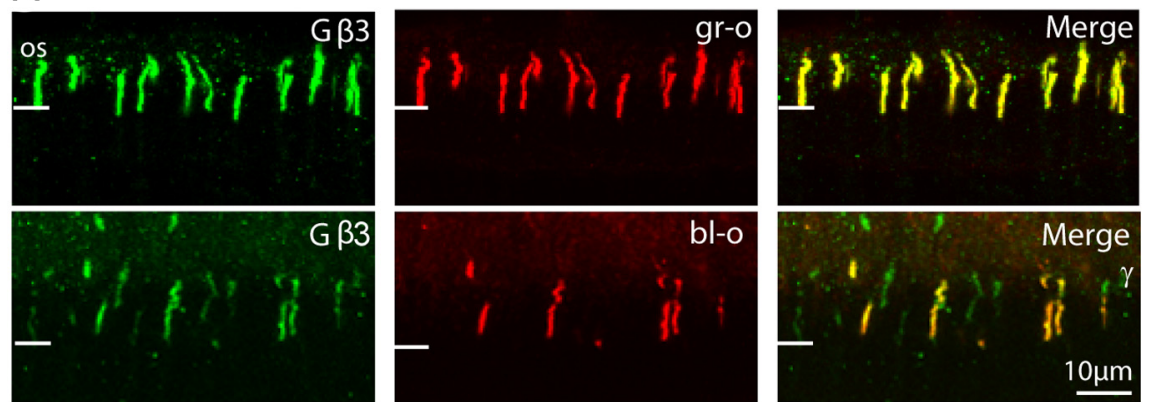

$\mathrm{B}$ WT
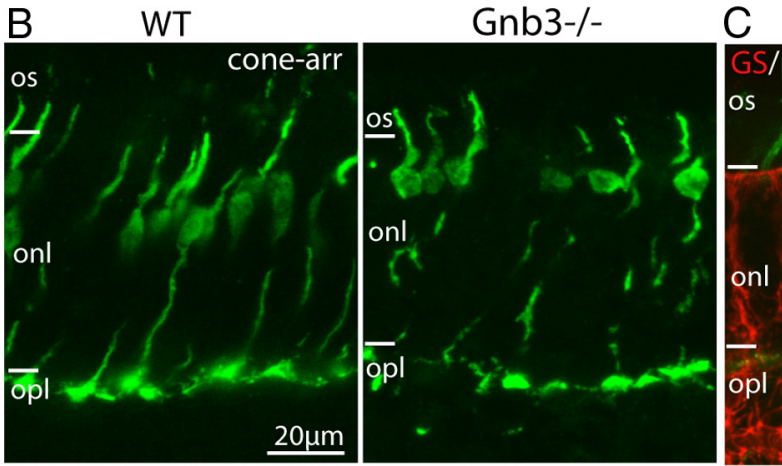

D

WT
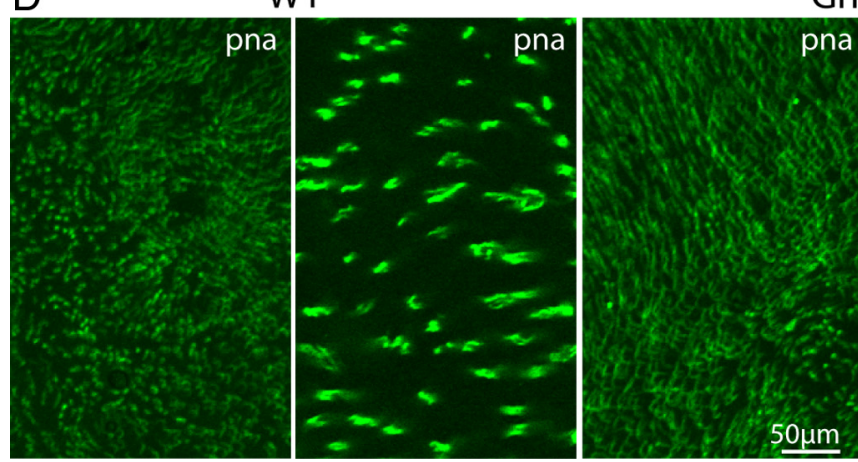

Gnb3-/-

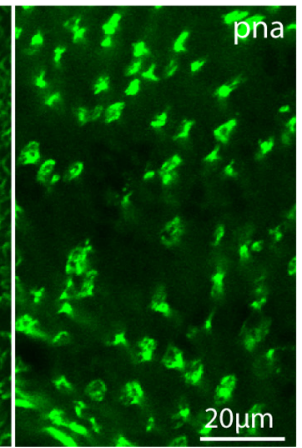

Figure 1. All cones express $G \beta 3$ and $G n b 3$-null cones appear normal. $A$, Coimmunostaining for $G \beta 3$ and green (gr-0, top) or blue (bl-0, bottom) opsin in a WT retina shows strong staining for $G \beta 3$ in cone outer segments expressing either opsin. $\boldsymbol{B}$, Immunostaining of WT and null ( $\left(\mathrm{Gnb} 3^{-1-}\right.$ ) retina with the cone-specific marker, cone arrestin (cone-arr), shows that Gnb3 $3^{-1-}$ cones have normal appearance and normal expression pattern of cone arrestin. $C$, Immunostaining of WT and Gnb3 ${ }^{-1-}$ retina for glutamine synthetase (red), shows similar staining pattern in the two genotypes, indicating absence of Muller cell proliferation in $\mathrm{Gnb}^{-1-}$. Cone outer segments labeled with PNA (green) show normal morphology in the Gnb3 ${ }^{-1-}$. D. Whole-mount retina staining for PNA shows normal cone density in the null retina (left two panels show WT at low and high magnification respectively; right two panels show KO). Three- to 8-week-old mice were used for these experiments. For this and subsequent figures: all immunostaining experiments were performed on at least 3 sets ( $\mathrm{KO}$ and WT), and the same imaging parameters were used for a set. 0s, Outer segments; onl, outer nuclear layer; and opl, outer plexiform layer.

M-pigment and, (2) comparison of UV to green light sensitivity ratio in dorsal retinal cones in WT mouse $(\sim 25 \%)$ and in S-pigment knock-out mouse $(\sim 10 \%)$ suggests a rather low level of S-pigment coexpression ( $\sim 15 \%$ relative to the M-pigment) (Nikonov et al., 2006; Daniele et al., 2011).

Response normalization. Light responses were quantified as a suppression of the cone circulating current passing through the cGMP-gated channels in the dark. For each cell, responses were normalized to its maximum (saturating) response, and normalized responses were averaged according to the stimulus intensity.

Because saturating responses correspond to the complete suppression of the cone circulating current, saturating response amplitude and circulating current have the same absolute value and therefore in this sense we used these terms interchangeably. During the experiment, the fraction of the circulating current collected by the suction pipette could change from its original value (most often a $\sim 25 \%$ increase) due to cell movement inside the pipette. To obtain an accurate estimate of the saturating response amplitude at all time points, short series of saturating responses were recorded at the beginning and the end of the recording session, and sometimes also at the middle of the experiment if needed. The amplitude of the circulating current present at the time of each subsaturating stimulation was estimated using linear interpolation on the time axis between the amplitudes of the two neighboring groups of saturating responses.

All saturating responses exhibited a brief transient "nose" component followed by a sustained phase (see Fig. 5). The latter corresponded to the complete closure of the cGMP-gated channels, as repeated stimulation of the cones during the plateau phase did not result in any additional light responses (Nikonov et al., 2008). To analyze the cGMP-dependent component of the response, the saturating amplitude was measured at the plateau level. Because the nose component was small and its relative contribution to the response was similar between genotypes [8 4 4\% (WT), $10 \pm 4 \%\left(\mathrm{Gnb3}^{+l^{-}}\right)$and $9 \pm 3 \%$ $\left(\mathrm{Gnb3}^{-1-}\right)$ (average $\left.\left.\pm 2 \mathrm{SEMs}\right)\right]$, the method of normalization should have negligible effect on our conclusions.

Quantitative analysis. Light responses were normalized to the maximum (saturating) response of a particular cell, and averaged according to the stimulus intensity. An exponential saturation function was used to fit response peak amplitude versus flash intensity data:

$$
r\left(t_{\text {peak }}\right) / r_{\text {max }}=1-\exp \left(-Q / Q_{e}\right),
$$

where $r\left(t_{\text {peak }}\right)$ is the response peak amplitude in picoamperes, $r_{\max }$ is the maximum response amplitude, $Q$ is the flash intensity in photons per $\mu \mathrm{m}^{2}$, and $Q_{\mathrm{e}}$ corresponds to the flash intensity at which the response amplitude is $\sim 63 \%$ of the maximum. In the linear intensity range (when $Q \ll Q_{\mathrm{e}}$ ) the above equation can be simplified to:

$$
r\left(t_{\text {peak }}\right) / r_{\max }=Q / Q_{\mathrm{e}} .
$$

Light sensitivity, defined as the slope of the normalized amplitude versus intensity curve in the linear intensity range, was estimated as $1 / Q_{\mathrm{e}}$, measured in (photons ${ }^{-1} \mu \mathrm{m}^{2}$ ). We crosschecked this estimate with another estimate of sensitivity obtained by measuring the peak amplitude of the normalized "single-photon" response (for $Q=1$ photon per $\mu \mathrm{m}^{2}$ ). The Lamb and Pugh activation model (Lamb and Pugh, 1992) was used to fit the rising phases of the normalized cone response families:

$$
r\left(t_{\text {peak }}\right) / r_{\max }=1-\exp \left[-1 / 2 \Phi A\left(t-t_{\text {eff }}\right)^{2}\right],
$$

where $\Phi$ is the number of photoisomerizatons per flash $\left(\Phi=Q \times a_{\mathrm{c}}\right), t_{\mathrm{eff}}$ is a short (a few ms) delay, and $A$ is the Lamb and Pugh amplification constant. We calculated $A$ as follows:

$$
A=\nu_{\mathrm{RE}} \times \beta_{\mathrm{sub}} \times n_{\mathrm{cG}},
$$

where $\nu_{\mathrm{RE}}$ is the rate of activation of phosphodiesterase subunits by a single excited pigment molecule, $\beta_{\text {sub }}$ is the catalytic activity of a phos- 
A
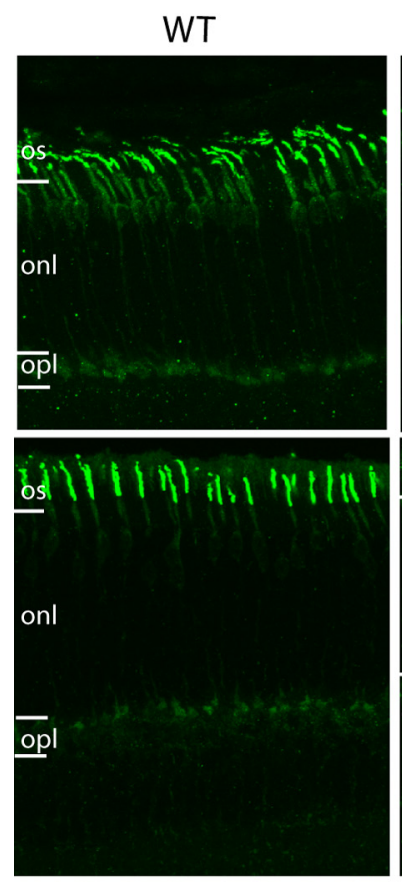

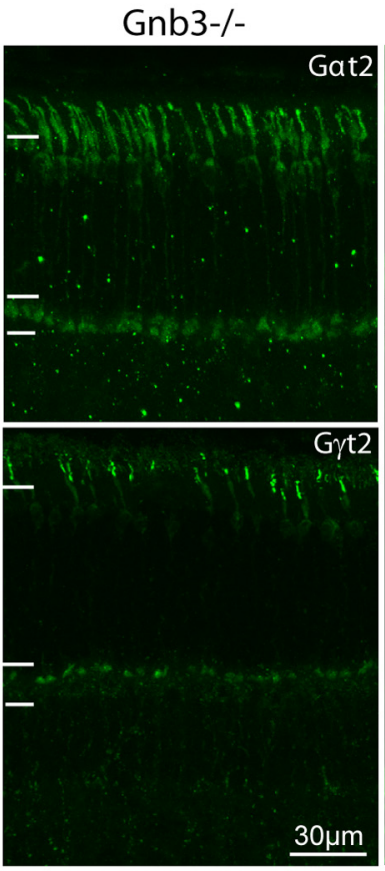

B

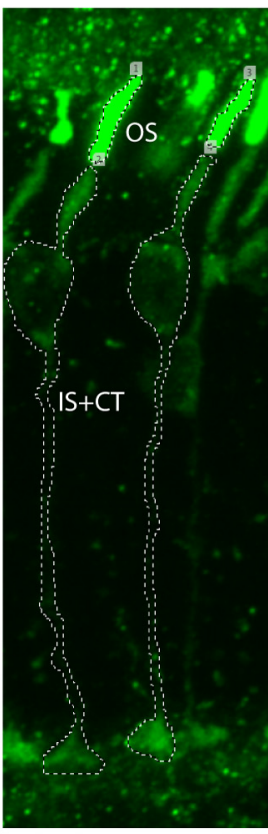

C
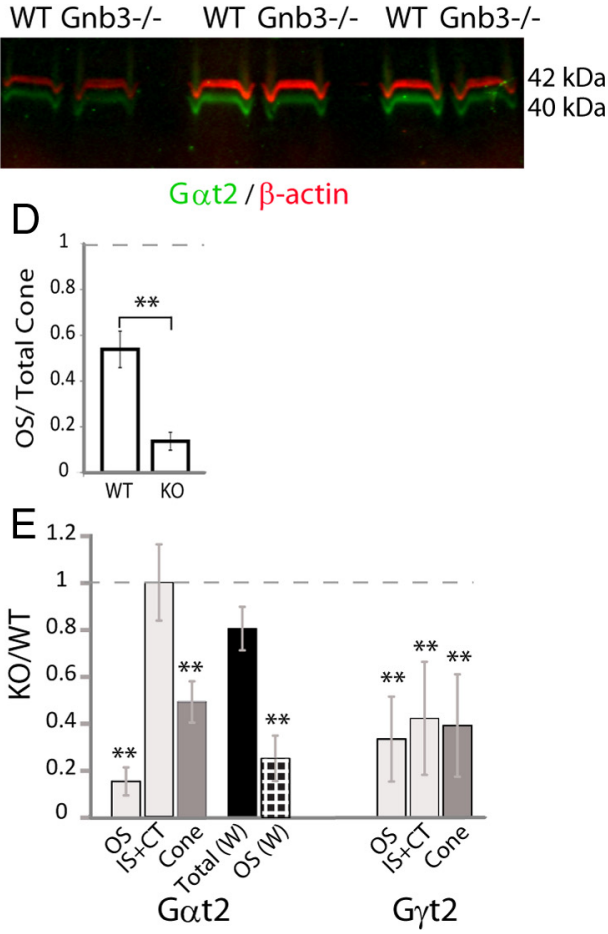

Figure 2. Cone transducin subunits are downregulated in $G n b 3^{-1-}$ cones. $A$, Immunostaining of WT (left) and null (right) retinas for cone transducin subunits $G \alpha \mathrm{t} 2$ (top) and $G \gamma t 2$ (bottom). Staining in the null retina is greatly reduced in the cone outer segments. $\boldsymbol{B}$, Representative WT cone image with different regions outlined for measuring fluorescence intensities using Volocity software. IS $+C T$, Inner segment and cone terminal. C, Western blot showing $G \alpha$ t2 expression (green) in the WT and null retina using the 0 dyssey system. The blots were also probed for $\beta$-actin (red) for normalization. Molecular weights are indicated on the side. $D$, Bar chart comparing staining intensity of $G \alpha t 2$ in the outer segments relative to total $G \alpha t 2$ in the cones (as shown in $B$ ) for the WT and $G n b 3^{-1-}$ retina. $E$, Bar chart showing expression levels in different regions of interest in the null cone relative to that in the WT. The three left bars: $0 S$, IS $+C T$, and cone (overall cone) were quantified from immunostaining. Total $(W)$ bar (black) represents the relative total expression as detected by Western blots and $0 S(W)$ bar (dotted) represents the relative expression level in $0 S$ as determined by combining immunostaining and Western blot data. $N=5$ sets for immunostaining and $N=7$ for Western blotting experiments. Dashed horizontal line indicates unity. Data are average \pm SEM. ${ }^{* *} p<0.01$.

phodiesterase subunit and $n_{\mathrm{cG}}$ is the Hill coefficient of the cGMP-gated channel.

Model traces were convolved with digital filters to incorporate effects of cone membrane time constant (set at $5 \mathrm{~ms}$ ) and the measured impulseresponse function of the hardware filter.

The combined hardware-related delay was measured by comparing, in the same cell, responses recorded at the standard settings (low-pass filter at $30 \mathrm{~Hz}, 200 \mathrm{~Hz}$ sampling rate) with the unfiltered responses sampled at $10 \mathrm{kHz}$. The delay was $\sim 11 \mathrm{~ms}$ and was not subtracted from the results presented here.

Custom scripts developed in the Matlab software (MathWorks) were used for extracting individual responses and data analysis.

Quantitative real-time RT-PCR. Total RNA from mouse retina was isolated with a Nucleospin RNA II kit (Macherey-Nagel). cDNA was synthesized with a high capacity cDNA reverse transcription kit (Applied Biosystems). Quantitative real-time PCR was performed with a Power SYBR Green kit (Applied Biosystems) on an Applied Biosystems 7500 Fast Real-Time PCR system. Melt curve analysis verified the specificity of the product. GAPDH was used as a reference gene for normalization, and analysis of relative gene expression was performed using the relative standard curve method per the manufacturer's protocol. The primer sequences were as follows ( $5^{\prime}$ to $\left.3^{\prime}\right)$ :

$\mathrm{G} \alpha \mathrm{t} 2$ : forward: tgc agt cca tcc tgg cca tca tca g; reverse: atc cgc aca gct tgg ctc tgc ata;

$\mathrm{G} \gamma \mathrm{t} 2$ : forward: tgc taa gct gat ggc cca ccc t; reverse: agg tat ccc agt aca ctt ggg cgt g;

GAPDH: forward: acg gcc gca tct tct tgt gca; reverse: ata cgg cca aat ccg ttc aca ccg;

G $\beta 2$ : forward: atg ttc ggg att cca tgt gcc gac; reverse: ggg gaa gaa agc cac ggc att ga;
G $\beta 4$ : forward: act tca act gca gtg tgt ggg acg; reverse: gtc atg acc agc aag gac acc tga $c$.

\section{Results}

\section{All cones express G $\beta 3$}

It was previously shown that cone outer segments express G $\beta 3$ (Fung et al., 1992; Lee et al., 1992; Peng et al., 1992; Huang et al., 2003; Ritchey et al., 2010; Dhingra et al., 2012). Here, we performed immunostaining with antibodies against $G \beta 3$ and cone opsins to test whether the expression of $\mathrm{G} \beta 3$ was present in all cones or was restricted to a type of cones. As the mouse retina is dichromatic, we tested for both blue-sensitive and greensensitive opsins. All outer segments that showed staining for blue or green opsins also stained strongly for $\mathrm{G} \beta 3$, thus establishing that all cones express $\mathrm{G} \beta 3$ (Fig. 1A). We previously reported that the general morphology of $G n b 3^{-1-}$ retina appears normal, but the spacing between somas in the outer nuclear layer was sometimes enlarged and some cone terminals viewed by electron microscopy appeared darker than in WT (Dhingra et al., 2012). We therefore examined the cones in 3 to 8 -week-old mice with additional methods. TUNEL staining, which detects nuclei that undergo DNA fragmentation, a key feature of apoptosis, did not reveal any increase in cone death compared with WT (data not shown). However, it still seemed possible that cones might undergo slow degeneration, and therefore we also examined cone morphology by immunostaining the WT and null retinas for cone arrestin. In the WT cones, staining for arrestin was present 
A
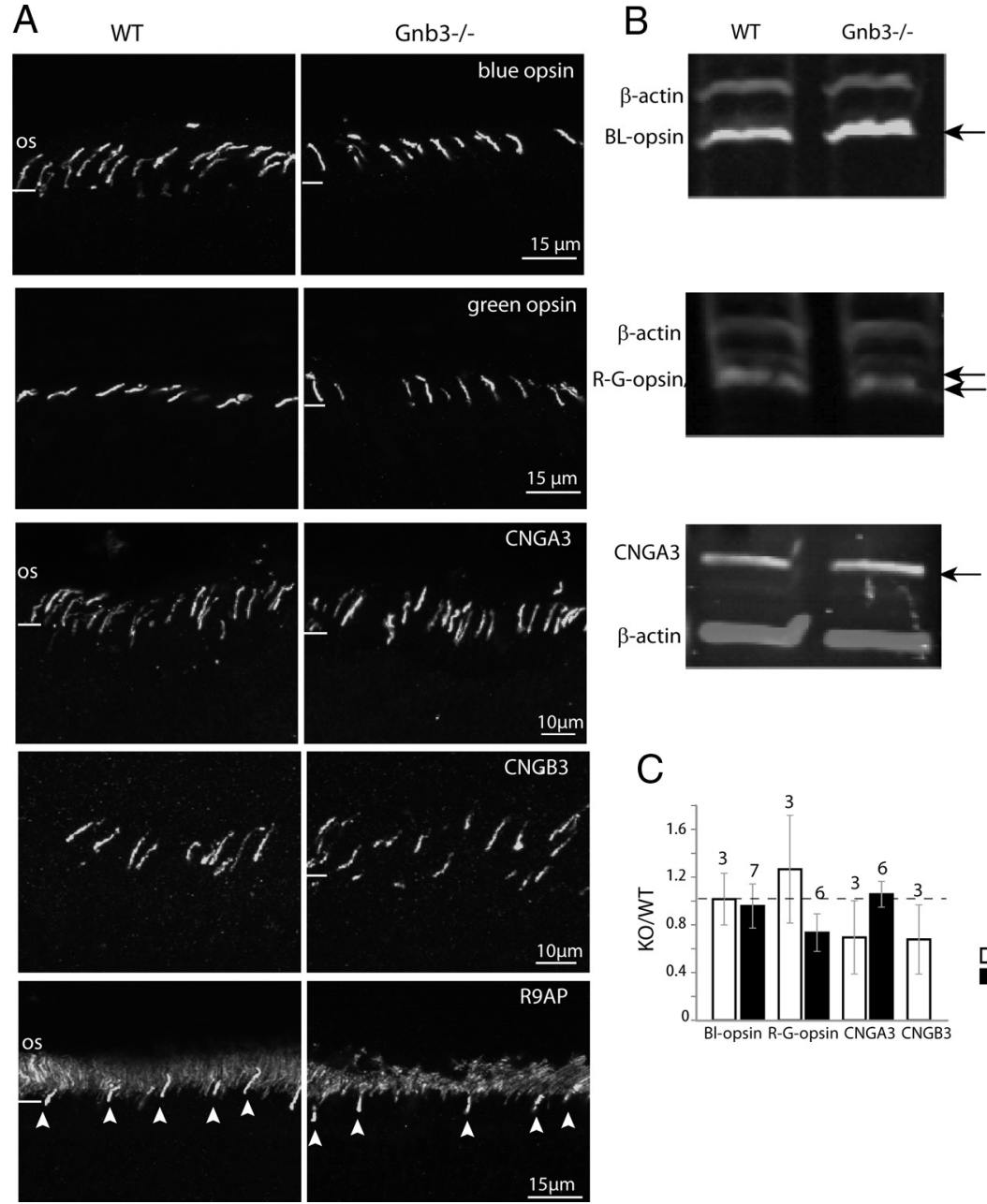

Figure 3. Expression of cone opsins and CGMP-gated cone channels is preserved in $\mathrm{Gnb} 3^{-/-}$cones. $A$, Immunostaining of WT and $G n b 3^{-1-}$ retina for (from top) blue and green opsins, cone CNG channel subunits CNGA3 and CNGB3, and R9AP. For the R9AP staining, arrowheads point to cone outer segments. $\boldsymbol{B}$, Representative immunoblots showing expression of cone opsins and CNGA3 (arrows) and $\beta$-actin for normalization in the WT and $G n b 3^{-1-}$ retina. C, Bar chart showing relative staining intensities in the $0 S$ and total retina (Western blotting). Expression levels of these proteins are similar between the WT and null retina. The number of sets examined for the experiments have been indicated above the bars. Data are average \pm SEM.
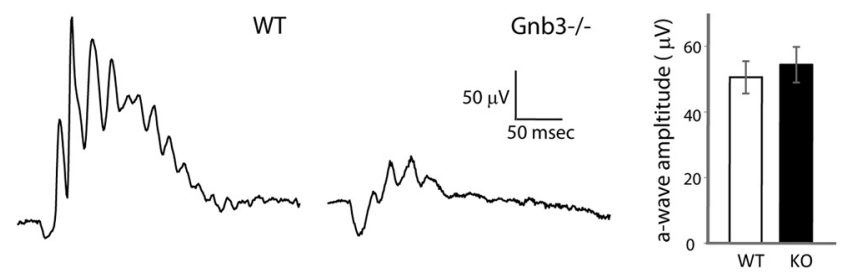

Figure 4. Photopic ERG is largely preserved in the $G n b 3^{-1-}$ mouse. Mice were light adapted with 30 scot $\mathrm{cd} \mathrm{m}^{-2}$ green background, and stimulated with $500 \mathrm{scot} \mathrm{cd} \mathrm{m}^{-2}$ white xenon tube. The negative going wave (representing activity in cones and off bipolar cells) is similar between the two genotypes.

throughout the cell, and it was particularly strong in the outer segments and in the cone pedicles. In the null retina, staining for arrestin revealed similar localization, suggesting little or no morphological changes (Fig. 1B). We further tested for induced gliosis because Muller cells are known to react to retinal degeneration/ injury by proliferation. Immunostaining for glutamine synthetase (GS) (Fig. 1C) and vimentin, two known Muller cell-specific markers, showed similar staining intensity and distribution in the WT and null retinas. We then tested the cone density by staining whole mount WT and null retina with PNA, a cone marker that labels extracellular matrix associated with cones. The null retina showed normal PNA staining pattern, with intense staining on the outer segments and weakly stained cone terminals, and the density of PNA labeled cones appeared similar to that in the WT (Fig. 1C,D). These experiments rule out any significant cone degeneration in the absence of G $\beta 3$ and establish that despite the absence of $\mathrm{G} \beta 3$ the cones remain fairly intact.

\section{Absence of $\mathrm{G} \beta 3$ reduces the expression of cone transducin subunits}

The expression and targeting of the three subunits of heterotrimeric G-proteins are generally mutually dependent (for review, see Marrari et al., 2007; Lobanova et al., 2008; Kolesnikov et al., 2011; Dhingra et al., 2012). We tested the expression levels of cone transducin $\alpha(\mathrm{G} \alpha \mathrm{t} 2)$ and cone transducin gamma ( $\mathrm{G} \gamma \mathrm{t} 2)$ by immunocytochemistry and Western blotting. In the $\mathrm{WT}$, staining for $\mathrm{G} \alpha \mathrm{t} 2$ was strong in cone outer segments with much lower intensity in the other compartments of the cone (Fig. 2A). In the $G n b 3^{-/-}$, the staining in the outer segment was greatly reduced, and there was hardly any difference in staining intensity between the outer and the inner segments (Fig. 2A). The G $\alpha$ t2 levels in the outer segments and in the rest of the cone (including inner segment, axon, and cone terminal) were quantified after outlining these compartments as shown in Figure $2 \mathrm{~B}$. Whereas in the WT, more than half $(54 \%)$ of the total $\mathrm{G} \alpha \mathrm{t} 2$ protein was concentrated in the outer segment, in the $G n b 3^{-/-}$, only $14 \%$ of the protein was in the outer segments (Fig. 2D). Comparing G $\alpha \mathrm{t} 2$ staining level in the outer segment of the null retina with that in the WT showed that it was reduced to $\sim 15 \%$ (ranging between 4 and $35 \%$ ) of that in the WT, although the level in the rest of the cone (IS+CT) was similar. The overall expression in the cones was less affected, with $\sim 50 \%$ of the WT level remaining when examined by immunohistochemistry or $\sim 80 \%$ by Western blotting (Fig. 2C,E). Immunocytochemistry-based fluorescence measurements are limited to the imaged area, and depending on imaging conditions, may not be linear with the protein levels. To double-check the relative level of G $\alpha \mathrm{t} 2$ in the null mouse, we adopted another approach in which we used the immunostaining data only to estimate the fraction of OS/ total G $\alpha$ t2 protein levels for cones in each retina and then used this fraction to "compartmentalize" data obtained by Western blotting (see Materials and Methods). This showed 25\% of the WT levels in the outer segments.

Next we examined the expression and localization of $\mathrm{G} \gamma \mathrm{t} 2$ by immunocytochemistry. In WT retina, this subunit is expressed specifically by cones and concentrates in the cone outer segment. The staining for this subunit was reduced in the outer segments of the null retina to $\sim 25 \%$ of WT levels (Fig. $2 A$, bottom, $D$ ). Because of its small molecular weight, this subunit could not be 
detected reliably by Western blots. In the heterozygous $(G n b 3+/-)$ retina, the staining intensity for $\mathrm{G} \beta 3$ in the outer segments was reduced to $\sim 40 \%$ (data not shown), and that for G $\alpha \mathrm{t} 2$ showed a downward trend to $\sim 85 \%$ of WT level, but the difference was not significant.

Downregulation of $\mathrm{G} \gamma \mathrm{t} 2$ in the $G n b 3^{-1-}$ retina could be because of reduction of the transcript level or due to effect on posttranscriptional processes. To test this, we performed quantitative real time RT-PCR for G $\gamma \mathrm{t} 2$ transcript levels and normalized them to the GAPDH levels. The average null to WT message level ratio was $1.32 \pm 0.19$; the difference in the levels between the WT and $G n b 3^{-1-}$ retina was not significant as determined by two-tailed $t$ test. As expected, the relative message levels for $\mathrm{G} \alpha \mathrm{t} 2$ in the two genotypes were also statistically similar with a null to WT message level ratio of $0.76 \pm 0.11$ ( 7 retinas of each genotype for each message; triplicates per retina).

\section{Absence of $\mathrm{G} \boldsymbol{\beta} 3$ does not affect other components of the cone cascade}

In the $\mathrm{ON}$ bipolar cell, $\mathrm{G} \beta 3$ is required for normal expression of all the key components of the signaling cascade, including the receptor (mGluR6), channel (TRPM1), and GAP complex (RGS11, R9AP, and G $\beta 5$ ) (Dhingra et al., 2012). To see whether $G \beta 3$ has a similar function in cones, we tested whether the absence of G $\beta 3$ affects components of the cone transduction machinery. Staining for blue and green opsins showed very similar expression pattern in the null and WT retinas and the staining intensities in the outer segments were comparable (Fig. $3 A, C)$. This result was confirmed by Western blotting (Fig. $3 B, C$ ). The staining pattern for the cone $\mathrm{CNG}$ channel subunits, CNGA3 and CNGB3, which are restricted to the outer segments in the WT also appeared normal in the null retina (Fig. 3A). Quantifying the levels of the CNG channel subunits in the outer segment showed them to be insignificantly lower (Fig. 3C). The level of total CNGA3 in the null retina as determined by Western blot analysis was the same as in the WT (Fig. $3 B, C$ ). As anti-CNGB3 antibody did not give a reliable signal in Western blotting, the level of this subunit was not tested by this method.

We next examined the expression of cone cascade modulator, R9AP, a protein that forms a tight complex with RGS9 and G $\beta 5$ (Hu et al., 2003; Martemyanov and Arshavsky, 2009). R9AP was concentrated in the cone outer segments (Fig. $3 A$, bottom) with no apparent difference in the expression levels in the WT and null retina. In summary, G $\beta 3$ deletion affected the expression and

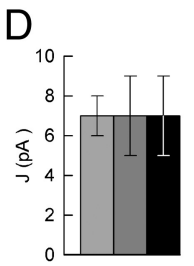

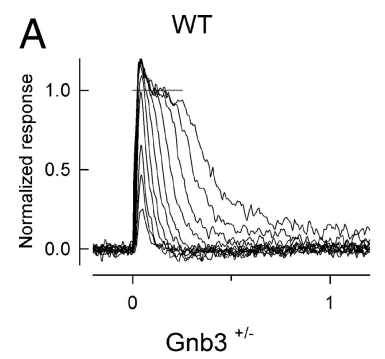
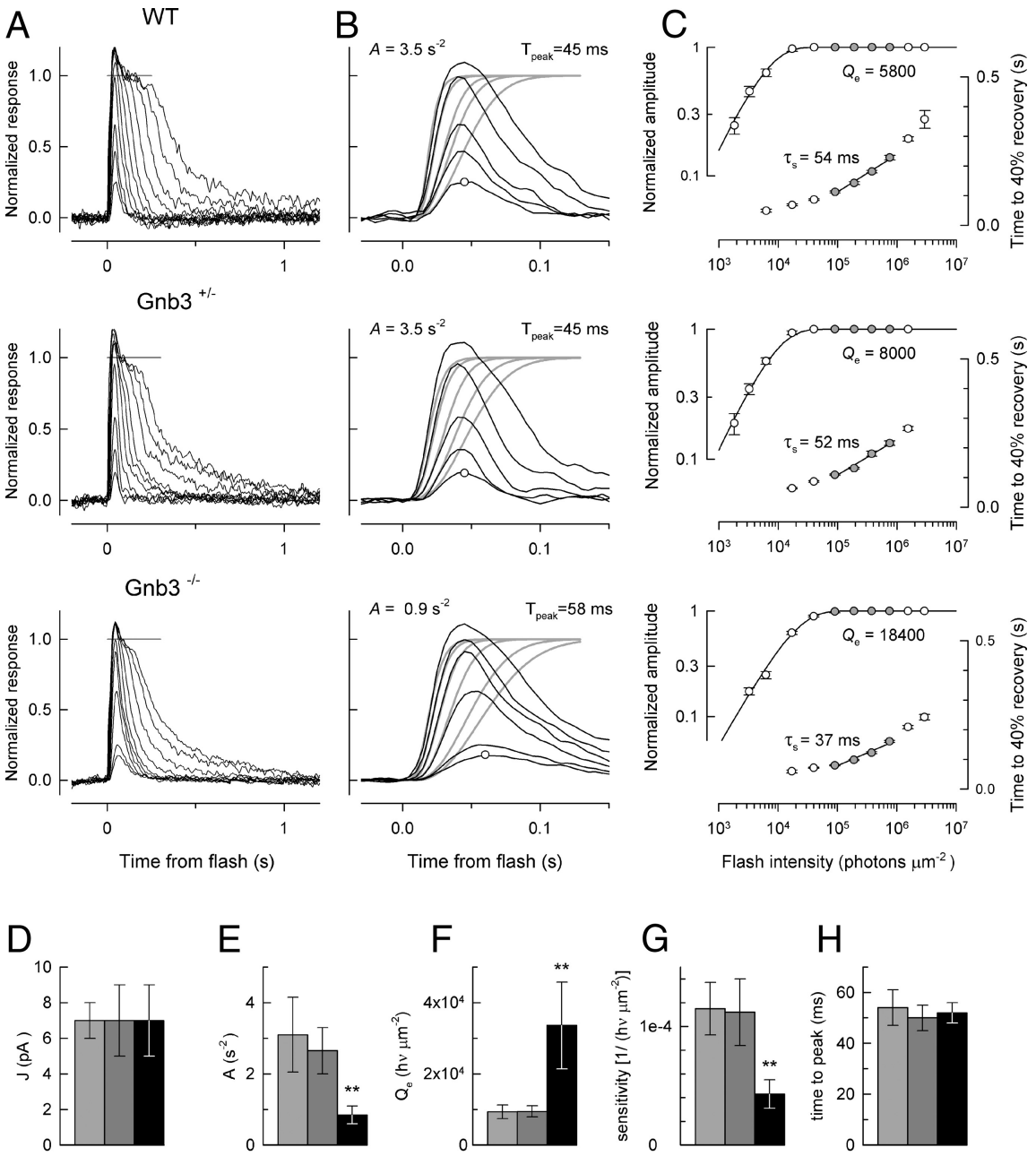

G

$\mathrm{H}$

Figure 5. Examples of flash response families and response analysis in cones. The first three rows present data recorded from a single cone of a particular genotype as indicated on the figure. A, Families of responses to a series of $5 \mathrm{~ms} 500 \mathrm{~nm}$ flashes of graded intensities. At least 60 individual responses were averaged for the dimmer flashes and at least 15 individual responses were averaged for the brighter flashes. The gray horizontal lines indicate estimated levels of the maximum (saturating) response amplitude corresponding to a complete closure of the light sensitive channels. The "nose" component above the gray lines was not light sensitive and was excluded from further analysis by the response normalization (see Materials and Methods). For each cell, responses were normalized to the saturating response amplitude (average of $6 \mathrm{pA}$ for WT and $\mathrm{Gnb} 3^{+/-}$and $8 \mathrm{pA} \mathrm{for} \mathrm{Gnb}^{-/-}$ cones). $\boldsymbol{B}$, Responses to the dimmer flashes from the response families of column $A$ were plotted on a faster time scale together with the Lamb and Pugh activation theory traces (thickened gray traces). Open circles are placed at the response peak to measure time to peak ( $\left.T_{\text {peak }}\right)$ from the dim-flash responses. The estimated values of the amplification constant " $A$ " and of $T_{\text {peak }}$ are indicated on the figure. C, Normalized peak response amplitude (left ordinates) and time to $40 \%$ recovery (right ordinates) versus flash intensity data measured from the response families of column A (filled symbols indicate data measured in the intensity range $\sim 10^{5}-10^{6}$ photons per $\mu \mathrm{m}^{2}$, note that recovery time is plotted on a linear scale and response amplitude and flash intensity on logarithmic scales). To measure the parameter $Q_{e}$ (flash intensity at which response amplitude is $\sim 0.63$ of the maximum), an exponential saturation function was fitted to the amplitude versus flash intensity data. To measure the recovery time constant, a linear regression line was fitted to recovery time versus log of flash intensity. The slope of the line per e-fold change in flash intensity estimates recovery time constant $\tau_{s} . \mathbf{D}-\boldsymbol{H}$, Population averages $\left(n=9,9,15\right.$ for WT, Gnb $3^{+/-}$, and $G n b 3^{-1-}$ records, respectively) for the maximum response amplitude $(\boldsymbol{D})$, the amplification constant $(\boldsymbol{E}), Q_{\mathrm{e}}(\boldsymbol{F})$, light sensitivity $\left(1 / Q_{e^{\prime}} \boldsymbol{G}\right)$, and time to peak (H) for WT (light gray), Gnb3 ${ }^{+/-}$(dark gray), and Gnb3 ${ }^{-1-}$ (black) cones $\left(n=14\right.$ for time to peak in $G n b 3^{-1-}$ ). ${ }^{* *} p<0.01$. In this figure, all error bars are \pm 2 SEMs.

localization of G-protein subunits, but did not affect the rest of the cascade components.

\section{Cone function in $\mathrm{Gnb3}^{-/-}$mice is partially preserved}

We previously reported that $G n b 3^{-1-}$ mice have a small conegenerated b-wave, indicating some residual ON cone bipolar cell activity (Dhingra et al., 2012). Here, we quantified the residual 

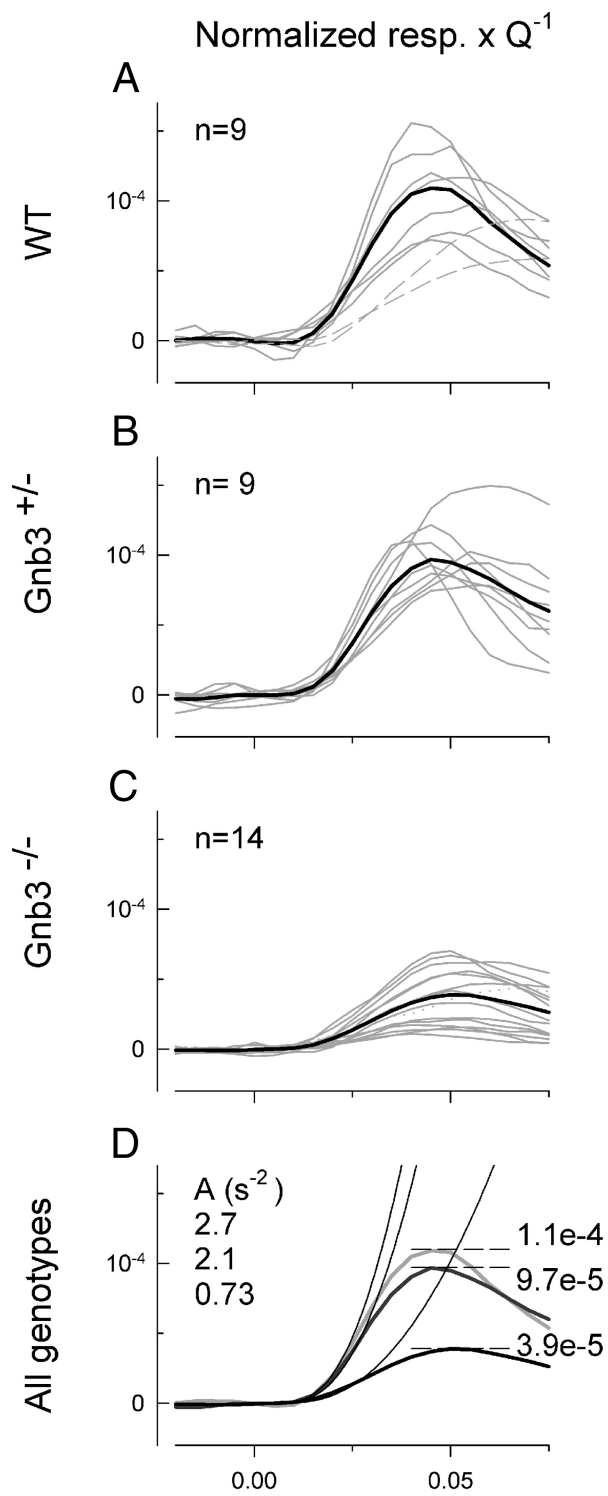

Time from flash (s)
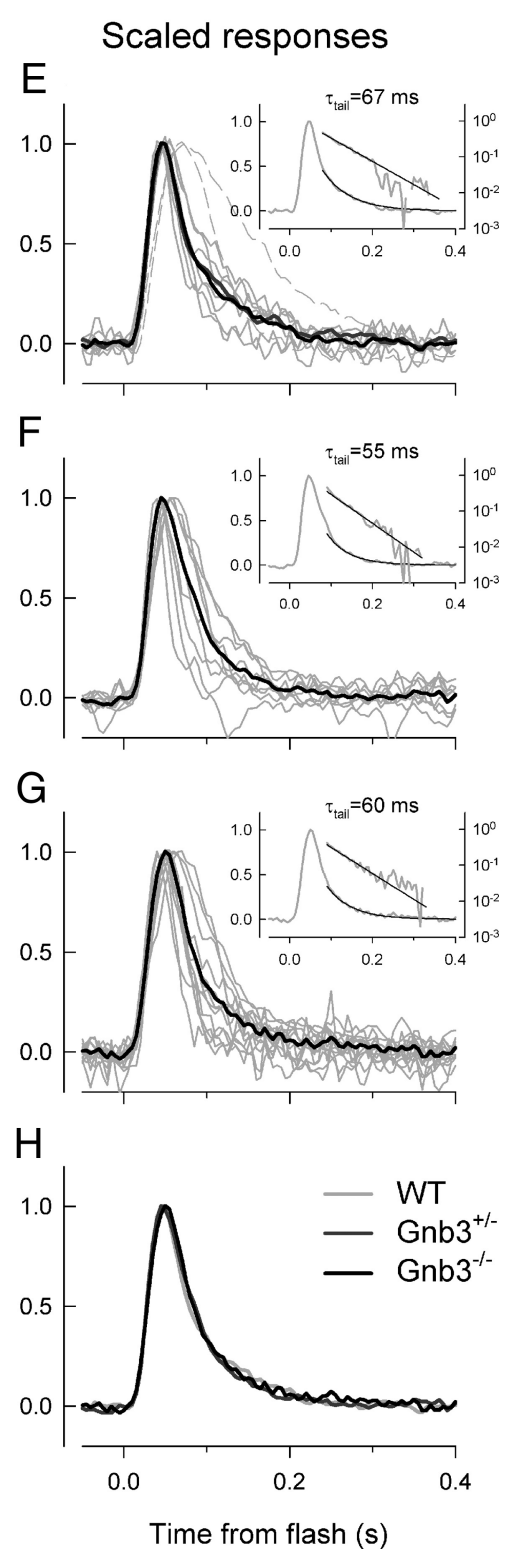

Figure 6. Dim-flash responses of $\mathrm{Gnb} 3^{-/-}$cones have reduced sensitivity and amplification whereas response kinetics are similar to those of WT. Responses to the dimmest flashes from the response families like those shown on Figure $5 A$ were divided by the corresponding flash intensity to calculate responses to 1 photon per $\mu \mathrm{m}^{2}$ for sensitivity and amplification analysis (left column), or scaled to the unity amplitude for the kinetic analysis (right column). The first three rows plot dim flash responses recorded from cones of a particular genotype as indicated on the figure. The individual responses are shown with thin gray traces, " $n$ " indicates the number of cone records for each genotype. Population averaged responses are shown with thickened black traces. The dashed gray traces in $\boldsymbol{A}$ and $\boldsymbol{E}$ show responses from two slow WT cones that were excluded from the population average. $\boldsymbol{A}-\boldsymbol{C}$, Normalized responses per photon. $\boldsymbol{D}$, Population averaged "single-photon" responses for the three different genotypes. Activation theory traces (thin black traces) calculated for a flash with intensity of 1 photon per $\mu \mathrm{m}^{2}$ were fitted to the population averaged responses and the values of the amplification constant are shown on the graph. The peak amplitudes are indicated with thin dashed lines. $\mathbf{E}-\mathbf{G}$, Dim-flash responses scaled to unity amplitude. The thickened dark gray trace in $\boldsymbol{E}$ that overlaps with black trace shows the M-dominant cone population-averaged response from Nikonov et al., 2006. The trace was shifted to the left by $14 \mathrm{~ms}$ to account for the difference in the hardware related delays in the current and previous studies ( 11 and $25 \mathrm{~ms}$ correspondingly). The inserts illustrate analysis of the tail phases of the population-averaged dim-flash responses. Averaged responses replotted from the corresponding panels (left ordinates, linear scales) and response tail phases (right ordinates, logarithmic scales) are shown on the same time axis with light gray traces. The slopes of the lines fitted to the response tail phases in the semilogarithmic coordinates give values of the $\tau_{\text {tail }}$ time constant, same $\tau_{\text {tail }}$ values were used to generate exponential traces for fitting response tail phases in the linear coordinates. $\boldsymbol{H}$, The normalized population averaged responses for the three different genotypes demonstrate the similar shape of the response.

cone responses, first by measuring the a-wave under photopic conditions using $30 \mathrm{scot} \mathrm{cd} \mathrm{m}^{-2}$ background light to suppress rod activity and a saturating white xenon flash that isomerized at least $0.5 \%$ of the $\mathrm{M}$-cone pigment and $0.1 \%$ of the UV-cone pigment in adult mice. The $G n b 3^{-1-}$ and WT mice showed very similar a-waves $[51 \pm 15 \mu \mathrm{V}$ in WT $(n=10)$ versus $54 \pm$ 21 in the $G n b 3^{-1-}(n=16)$ ] (Fig. 4). This suggested that cones in $G n b 3^{-1-}$ mice are functional, but because the conegenerated a-wave includes a contribution from activity of OFF bipolar cells, it did not provide an unambiguous signal to assess cone function.

\section{Gnb3 ${ }^{-/-}$M-dominant cones saturate normally but have lower amplification constant and sensitivity}

To more closely study the effects of G $\beta 3$ deletion on cone transduction, we recorded light responses to a series of $500 \mathrm{~nm} 5 \mathrm{~ms}$ flashes of graded intensities from 9 WT, 9 Gnb3+/-, and $15 \mathrm{Gnb3}{ }^{-/-}$M-dominant cones. Both $\mathrm{Gnb3}^{+/-}$and $\mathrm{Gnb3} 3^{-1-}$ cones produced robust and stable light responses over the course of the experiment (usually $\sim 30 \mathrm{~min}$ ) (Fig. 5A). Unless stated otherwise, all measurements given here were averaged from all the recorded cones. The amplitude of the saturating responses was very similar for the three genotypes $(6-8 \mathrm{pA}$ for the cells shown in Fig. 5) with an average of $7 \pm 1 \mathrm{pA}$ (average \pm 2 SEMs) for WT, $7 \pm 2 \mathrm{pA}$ for $G n b 3^{+/-}$, and $7 \pm 2 \mathrm{pA}$ for Gnb3 ${ }^{-1-}$ (Fig. 5D).

Next, we measured response efficiency using two well described parameters, the amplification constant $(A)$ and the flash sensitivity. The amplification constant was calculated by fitting Lamb and Pugh (1992) activation theory traces to the rising phases of the cone light responses as shown in the examples of Figure $5 B$. Because the amplification constant depends on the light collecting area, we first confirmed that this area in WT and $G n b 3^{-1-}$ cones is the same; opsin levels were also similar (Fig. 2). We found that the amplification constant of the WT and $\mathrm{Gnb3}^{+/-}$cones was similar (average: $3.1 \pm 1.1 \mathrm{~s}^{-2}$ for WT, $2.7 \pm 0.7$ for $G n b 3^{+/-}$), but that of the $G n b 3^{-1-}$ cones was nearly 4 times lower $\left(0.85 \pm 0.25 \mathrm{~s}^{-2}\right)$ (Fig. $5 E$ ). A similar reduction was observed when we calculated the amplification constant from "single-photon" responses. These responses were extracted by dividing the responses to the dimmest flashes (dim-flash responses) by the corresponding flash intensities and averaged across cells for each genotype (Fig. 6A-C). The corresponding values were 2.7, 2.1, and $0.73 \mathrm{~s}^{-2}$ for the WT, $\mathrm{Gnb3}^{+/-}$, and $\mathrm{Gnb3}^{-/-}$respectively (Fig. 6D).

To estimate the light sensitivity of the cones, we fitted exponential saturation functions to the normalized peak amplitude versus flash intensity data as shown in Figure $5 C$, and determined 
the value of $Q_{\mathrm{e}}$, the intensity at which the response amplitude reaches $1-1 /$ e (i.e., $\sim 0.63$ ) of the maximum amplitude. The average $Q_{\mathrm{e}}$ value was very similar for WT $\left(9300 \pm 1900\right.$ photons $\left.\mu \mathrm{m}^{-2}\right)$ and $\mathrm{Gnb3}^{+/-}\left(9400 \pm 1600\right.$ photons $\left.\mu \mathrm{m}^{-2}\right)$, but was much higher for $G n b 3^{-1-}$ $\left(34,000 \pm 12,000\right.$ photons $\mu \mathrm{m}^{-2}$ ) (Fig. $5 F)$. Thus, the response amplitude versus flash intensity curve for the Gnb3 ${ }^{-1-}$ cones was shifted to approximately fourfold higher intensities compared with the WT. Sensitivity estimated as $1 / Q_{\mathrm{e}}$ (see Materials and Methods) was also similar in WT $\left(1.15 \mathrm{e} \pm 0.22 \times 10^{-4}\right.$ photons $^{-1}$ $\left.\mu \mathrm{m}^{2}\right)$ and $\mathrm{Gnb3}^{+/-}\left(1.12 \pm 0.19 \times 10^{-4}\right.$ photons $^{-1} \mu \mathrm{m}^{2}$ ) and approximately three times lower in $G n b 3^{-1-}$ (4.3 \pm $2.3 \times 10^{-5}$ photons $^{-1} \mu \mathrm{m}^{2}$ ) (Fig. 5G). Similar results were also obtained by comparing the "single-photon" responses computed from the dimmest flash responses (Fig. 6D).
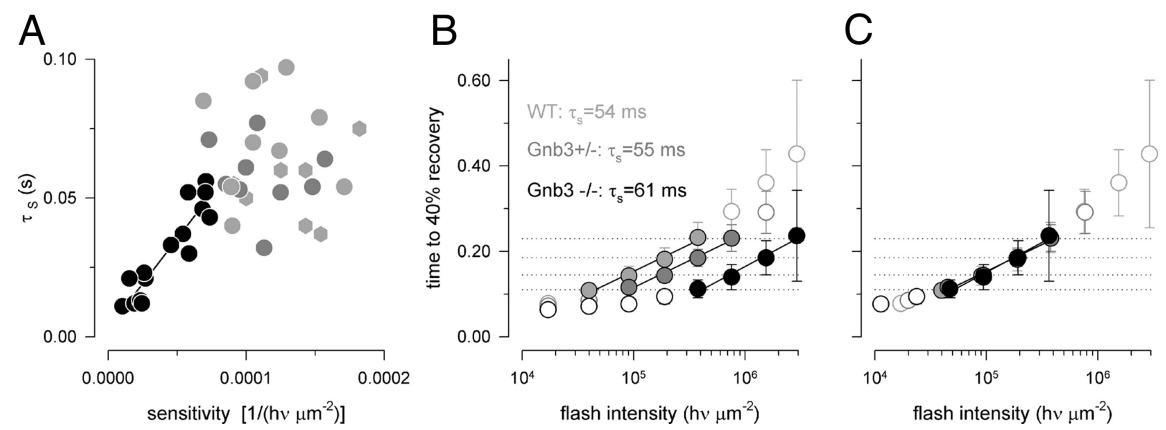

Figure 7. Saturating responses in $\mathrm{Gnb}^{+/-}$and $\mathrm{Gnb}^{-1-}$ cones recover with normal kinetics, and the same response durations as in WT are achieved with brighter intensities. $A$, Recovery time constant measured in the intensity range $\sim 10^{5}-10^{6}$ photons per $\mu \mathrm{m}^{2}$ (as in Fig. 5) for all cones in the current study versus light sensitivity (filled light gray circles for WT, filled dark gray circles for $\mathrm{Gnb}^{+/-}$and filled black circles for $\mathrm{Gnb} 3^{-/-}$cones). WT M-dominant cone data from the study of Nikonov et al., 2006 (light gray hexagons) are also added for comparison. A linear regression line was fitted to the $G n b 3^{-1-}$ data points, with a correlation coefficient of 0.85 . Data taken from WT and $G n b 3^{+/-}$were not correlated. $\boldsymbol{B}$, Time to $40 \%$ recovery versus flash intensity for each genotype. The data measured from saturating responses used for the "Pepperberg" analysis is plotted with filled circles. The dimmest flash used for the analysis is estimated as $99 \%$ saturating for the WT and $100 \%$ saturating for the Gnb $3^{+/-}$ and $G n b 3^{-1-}$ cones. The slopes of the straight lines give values of recovery time constant $\tau_{\mathrm{s}}$ as indicated on the figure. The dotted horizontal lines show that responses of the $\mathrm{Gnb} 3^{+/-}$and $\mathrm{Gnb}^{-1-}$ cones have similar durations to those of WT but at $2 \times$ and $8 \times$ brighter flash intensities. C, All data fall on the same trajectory after shifting $G n b 3^{+/-}$and $G n b 3^{-1-}$ graphs from $\boldsymbol{B}$ to the left on the intensity axis (by $2 \times$ and $8 \times$ correspondingly). Error bars are \pm 2 SEMs.

\section{Recovery kinetics is unaffected in $\mathrm{Gnb3} 3^{-/-}$cones}

We compared the kinetics of response to dim and saturating stimuli in the different genotypes. The time to peak was measured from individual responses to dim flashes (as shown in Fig. 5B) and averaged for each genotype. Corresponding values were $54 \pm$ $8 \mathrm{~ms}$ for WT, $50 \pm 5 \mathrm{~ms}$ for $\mathrm{Gnb} 3^{+/-}$, and $52 \pm 4 \mathrm{~ms}$ for $\mathrm{Gnb} 3^{-1-}$ (Fig. $5 H$ ). We also looked at the population averaged responses obtained by averaging the dim-flash response traces for each genotype (Fig. $6 E-G$ ); the general shape appeared similar (Fig. $6 H)$. The recovery phase of the dim-flash response was well described by a single exponential decay trace and the corresponding time constants $\left(\tau_{\text {tail }}\right)$ for the three genotypes were indeed similar: 67 for WT, 55 for $G n b 3^{+/-}$and $60 \mathrm{~ms}$ for $G n b 3^{-1-}$ (Fig. 6E-G). The average response shape recorded in this study was also identical to that recorded from WT $\mathrm{M}$-dominant cones in a previous study performed on a different physiology rig (Fig. 6E) (thick gray trace, redrawn from Nikonov et al., 2006).

A standard way to characterize recovery kinetics in phototransduction is the "Pepperberg" analysis (Pepperberg et al., 1992). This analysis quantifies recovery kinetics after bright saturating flashes. It was first developed for rod responses for which the slope of the line fitted to the response duration versus flash intensity data in a semilogarithmic coordinates provides an estimate of the life time of the activated G $\alpha$ t-PDE complex (Krispel et al., 2006). The applicability of the analysis to cones is less certain. A critical condition for the applicability is that responses should remain in saturation long enough for internal calcium (a known regulator of the recovery processes) to drop to its lowest level. This condition was harder to satisfy in $G n b 3^{-1-}$ cones where it was frequently problematic to obtain saturating responses at a number of different flash intensities due to the much reduced light sensitivity. When responses in the same intensity range $\left(\sim 10^{5}-10^{6}\right.$ photons per $\left.\mu \mathrm{m}^{2}\right)$ for all three genotypes were analyzed (Fig. $5 C$ ) the slopes measured for the $\mathrm{Gnb3}^{-1-}$ cones were generally shallower than those measured for WT and $G n b 3^{+/-}$. For $G n b 3^{-/-}$cones the decrease in the slope correlated with the decrease in sensitivity (correlation coefficient 0.85) (Fig. 7A). However, although all flashes in the "Pep- perberg" series produced saturating responses for the particular $G n b 3^{-l-}$ cone in Figure $5 C$, the dimmer flashes in the series were not completely saturating for some other $G n b 3^{-1-}$ cones that had lower sensitivities, invalidating conditions for the applicability of the analysis. One solution to the problem may be to adjust the intensity range for each cell based on its sensitivity and average the measured slopes for each genotype. However, this approach might introduce subjectivity in selecting intensity ranges for individual cells. A simpler approach is to compare slopes measured from the population averaged data as shown in Figure $7 B$. These slopes were similar; $\tau_{s}: 54,55$, and 61 ms for WT, Gnb3 $3^{+/-}$and $G n b 3^{-1-}$ cones. This strongly suggested that the bright flash recovery was not affected by deleting $\mathrm{G} \beta 3$. To further demonstrate this point, we shifted $G n b 3^{+/-}$and $G n b 3^{-1-}$ data points on the intensity axis to the left $(2 \times$ and $8 \times$ correspondingly). This resulted in almost complete overlap with the WT data (Fig. 7C), consistent with the idea that, provided the flash activates the same number of PDE molecules, the deactivation time course is the same independent of genotype.

Notably, the close similarity that was observed in the values of the $\tau_{\text {tail }}$ and $\tau_{\mathrm{s}}$ time constants suggests that either of them may be used for the estimation of the dominant recovery time constant as reported for amphibian rods (Nikonov et al., 1998).

\section{Both UV- and green-sensitive cones in $\mathrm{Gnb3}^{-/-}$mice are functional}

Our light stimulus in the suction electrode recording rig was limited to visible light. To test whether the UV-sensitive cones were also functional, we turned back to ERG recordings. We used a $10 \mathrm{~Hz}$ flicker rather than single flashes to allow for a larger number of repetitive stimuli and responses to be averaged. We determined the amplitudes of the flicker responses (peak to peak) at various intensities of the stimuli for two wavelengths $\lambda=365$ $\mathrm{nm}$ and $\lambda=513 \mathrm{~nm}$. As expected, due to the reduction in the ERG b-wave, the response in $G n b 3^{-1-}$ to flicker of either wavelength was greatly reduced (Fig. $8 A, B$ ). Responses to dim light were linear (presented as a slope of unity on a log-log intensity response scale), and this linear range was used to compute sensi- 
A
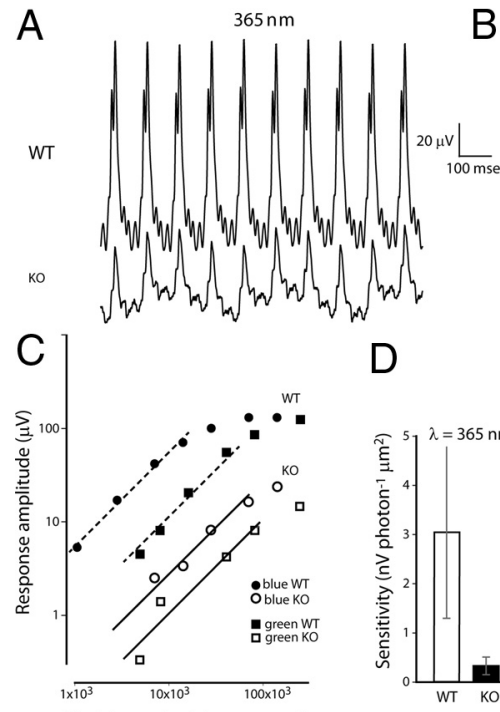

Flash intensity (photons $\mu \mathrm{m}^{-2}$ )
B

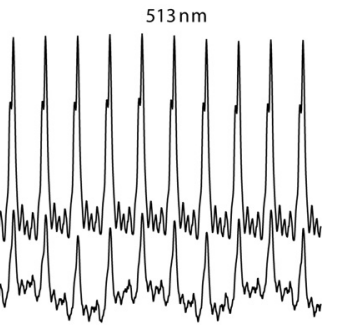

E
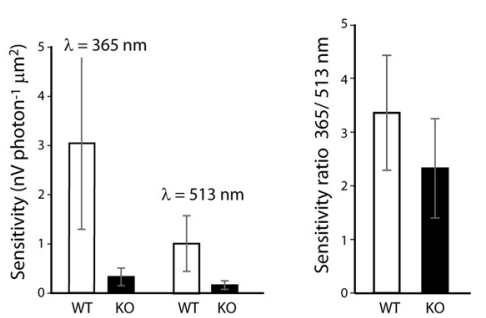

Figure 8. Both green-sensitive and blue-sensitive cones are functional in the absence of $\mathrm{G} \beta 3$. $\boldsymbol{A}, \boldsymbol{B}$, Ten hertz flicker ERG responses elicited by $\gamma=365(\boldsymbol{A})$ and $513 \mathrm{~nm}(\boldsymbol{B})$ flashes delivering $\sim 140,000$ and 240,000 photons $/ \mathrm{mm}^{2}$ at the cornea on a background illumination of 30 scot $\mathrm{Cd} \mathrm{m}^{-2}$ in WT and KO (Gnb3 ${ }^{-1-}$ ) mice. C, Response amplitude versus intensity functions (plotted on logarithmic coordinates) for cone-driven flicker responses in a WT and Gnb3 $3^{-1-}$ mice. Lines of unity slope, that represent linear relationships between peak amplitude and intensity, were fitted to the four lowest points. These values for the null mouse were 0.28 and 0.099 respectively. $\boldsymbol{D}$, Sensitivity of the $10 \mathrm{~Hz}$ flicker responses to stimulation of 365 and $513 \mathrm{~nm}$ for WT $\left(3.0 \pm 1.7\right.$ and $\left.1.01 \pm 0.56 \mathrm{nV}_{\text {photon }}{ }^{-1} \mu \mathrm{m}^{2}, n=5\right)$ and $G n b 3^{-1-}$ $\left(0.33 \pm 0.18\right.$ and $0.16 \pm 0.09 \mathrm{nV}$ photon $\left.{ }^{-1} \mu \mathrm{m}^{2}, n=4\right)$ mice. $\boldsymbol{E}$, The ratio of 365 sensitivity to visible light sensitivity from data in $C$ :WT $(3.36 \pm 1.07, n=5)$ and $G n b 3^{-1-}(2.32 \pm 0.92$, $n=4)$.

A

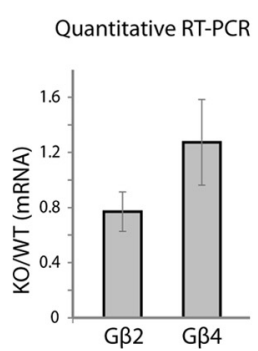

B

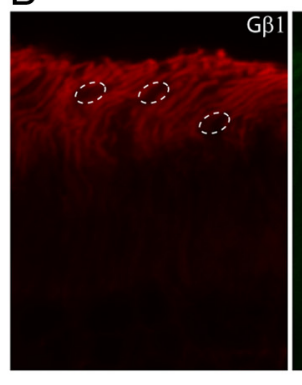

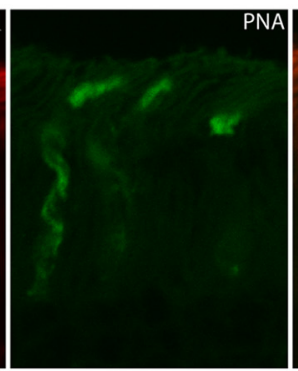

light was not statistically significant and may be a subject of further investigation. To ensure that the remaining response was due to cone function (rather than rods), we computed the ratio of sensitivity to 365 and $513 \mathrm{~nm}$, a measure of relative functionality of $\mathrm{S}$ and L/M pigment-driven pathways (and a signature of cone vs rod functionality). We found the ratio of sensitivity at $365 \mathrm{~nm}$ to that at $513 \mathrm{~nm}$ to be $3.36 \pm 1.07 \mathrm{in} \mathrm{WT}$ $(n=5)$ and $2.32 \pm 0.92$ in $\operatorname{Gnb3}^{-1-}(n=4)$. These values are within normal range (2-4) for WT cones (Lyubarsky et al., $1999,2002)$ and are considerably different from the expected ratio of 0.3 if the response was due to rod-driven activity. This indicated that both $\mathrm{S}$ and $\mathrm{L} / \mathrm{M}$ cones remained functional in the absence of $\mathrm{G} \beta 3$.

In $\mathrm{Gnb3} 3^{-/-}$cones, $\mathrm{G} \beta 1,2$, and 4 subunits are not expressed A cone-driven light response in the absence of $G \beta 3$ raised a key question: do the $G n b 3^{-1-}$ cones function using another $\beta$ subunit, or is the G-protein heterotrimeric complex not absolutely required for the response? We previously reported that neither antibodies against $G \beta 2$ nor against $G \beta 4$ gave any staining in the $\mathrm{Gnb3}^{-1-}$ retina (Dhingra et al., 2012). To rule out any small upregulation of these $\mathrm{G} \beta$ subunits, we also checked for an increase in the corresponding mRNA levels by quantitative RT$\mathrm{PCR}$, a more sensitive approach to detect gene upregulation. The ratio of the amplified message of $G \beta 2$ from the null retina to that of the WT was $0.73 \pm 0.14$, and that for $\mathrm{G} \beta 4$ was $1.02 \pm 0.32$ (4 retinas of each genotype, triplicates per retina); these levels were not statistically different between the WT and $\mathrm{Gnb3}^{-/-}$cones (Fig. 9A). As for $\mathrm{G} \beta 1$, because it is highly expressed in rods, RT-PCR seemed unlikely to show cone-related differences between the 2 genotypes. We therefore labeled cones with PNA and immunostained for $\mathrm{G} \beta 1$. The expression of $\mathrm{G} \beta 1$ was clearly confined to the rods, with cones outlined by PNA being clear of any $\mathrm{G} \beta 1$ staining (Fig. $9 B)$, thus ruling out any significant compensatory expression of another $\beta$ subunit.

\section{Discussion}

The expression of G $\beta 3$ in cones is conserved across vertebrate species including mammals (Ritchey et al., 2010); however, its role in cone phototransduction has not been directly examined. Studies in chicken have determined that a naturally occurring mutation (D153del) in Gnb3 gene is associated with an autosomal-recessive retinopa-

tivity (in $\mathrm{nV}$ photon ${ }^{-1} \mu \mathrm{m}^{2}$ ). For both wavelengths, the lines fitted to the $G n b 3^{-1-}$ data-points are shifted to the right relative to the WT lines; this indicates a significant reduction in sensitivity (Fig. 8C,D). Reduction at $365 \mathrm{~nm}$ was approximately ninefold, and at $513 \mathrm{~nm}$ was approximately sixfold. The sensitivity measured by flicker ERG recordings was reduced more than that measured by suction electrode recordings (sixfold to ninefold vs threefold to fourfold decrease). The reason for this apparent discrepancy is that the flicker response reflects the summation of all cone-driven responses including the $\mathrm{ON}$ and OFF cone bipolar cells' activity, and responses in the $G n b 3^{-1-}$ mouse ON bipolar cells are greatly compromised due to G $\beta 3$ 's involvement in the mGluR6 cascade (Dhingra et al., 2012). The higher loss in flicker sensitivity in response to UV light relative to the green thy, globe enlargement (rge) phenotype, leading to retinal degeneration and total visual loss (Montiani-Ferreira et al., 2005, 2007; Tummala et al., 2006; Ritchey et al., 2010, 2012). However, in chicken, G $\beta 3$ is expressed by both rod and cone photoreceptors, and the rge phenotype with retinal degeneration associated with the destabilizing mutation further complicates the analysis of exact role of $\mathrm{G} \beta 3$.

Here, using a $G n b 3^{-1-}$ mouse, we find that $\mathrm{G} \beta 3$ is required for normal expression and distribution of its partners, G $\alpha \mathrm{t} 2$ and $\mathrm{G} \gamma \mathrm{t} 2$; however, the absence of $\mathrm{G} \beta 3$ does not eliminate cone phototransduction or disrupt normal morphology. Rather, $G n b 3^{-/-}$cones respond with a decreased amplification and light sensitivity that correlates with the remaining level of $\mathrm{G} \alpha \mathrm{t} 2$ in the cone outer segment. 
G $\beta 3$ is required for proper localization of cone transducin, but not for other cascade elements or viability

We show that in the Gnb3 $3^{-1-}$ cone outer segments, the levels of $\mathrm{G} \alpha \mathrm{t} 2$ and $\mathrm{G} \gamma \mathrm{t} 2$ were reduced to $\sim 25 \%$ of the WT. Although the mechanisms involved in assembly and trafficking of G-protein subunits are not well understood, it has been shown that nascent $G \beta$ subunits in association with chaperone proteins initiate the formation of a complex with $\mathrm{G} \gamma$ and eventually $\mathrm{G} \alpha$ subunit for proper membrane targeting of the heterotrimer (reviewed by Marrari et al., 2007). Indeed, in $\mathrm{G} \beta$ e mutant flies that express very low levels of the eye specific $\mathrm{G} \beta$ subunit, $\mathrm{G} \alpha$ subunit shifts to the cytoplasm from a predominantly membrane localization in WT flies (Dolph et al., 1994). Similarly, in mouse $G n g 1^{-1-}$ rod outer segments, $G \alpha t 1$ and $\mathrm{G} \beta 1$ levels are downregulated; in $\mathrm{Gnb3}^{-1-} \mathrm{ON}$ bipolar cells, both $\mathrm{G} \alpha_{\mathrm{o}}$ and $\mathrm{G} \gamma 13$ are downregulated; and in $\mathrm{Gng}^{-1-}$, Gai3 levels in the brain are downregulated (Schwindinger et al., 2004; Lobanova et al., 2008; Kolesnikov et al., 2011; Dhingra et al., 2012). In the case of ON bipolar cells, G $\beta 3$ is important for proper expression of almost all other cascade proteins (Dhingra et al., 2012). Unlike its effects in bipolar cells, the absence of $\mathrm{G} \beta 3$ caused little or no mislocalization of other cone cascade components including opsins, CNG channel and arrestin. Thus, our results support the general hypothesis that the stability and trafficking of G-protein subunits are mutually dependent (Evanko et al., 2000; Marrari et al., 2007), and highlight overlapping yet distinct roles adopted by $\mathrm{G} \beta 3$ in cones and bipolar cells.

It is well documented that lack of some cascade components, but not others, may lead to degeneration; e.g., cones lacking CNGA3 and CNGB3 do degenerate, but those that have a mutation in Gnat2 (Got2) do not (Brockerhoff et al., 2003; Michalakis et al., 2005; Chang et al., 2006; Xu et al., 2011). When Gng1 is deleted, depending on the strategy used for generating the null mouse, rods degenerate either faster (Lobanova et al., 2008) or slower (Kolesnikov et al., 2011). In contrast, in the Gnb3 ${ }^{-1-}$ mouse, the cones hardly change their appearance, they do not degenerate, and they remain functional for at least 7 months (Dhingra et al., 2012). The finding that cones remain intact in the absence of $\mathrm{G} \beta 3$ allowed us to test the cone functionality in this mouse.

\section{Elimination of the $\boldsymbol{\beta}$ subunit does not affect efficiency of transducin activation}

A key finding from this study is that despite the absence of $G \beta 3$ and with reduced levels of $\mathrm{G} \alpha \mathrm{t} 2$, both green-sensitive and UV-sensitive cones respond reliably to light. This is based on the following observations: the average a-wave amplitudes of saturating responses to photopic stimulus were very similar between the WT and the null retina; data from flicker recordings showed that both blue-sensitive and green-sensitive cones retain light responses; in the suction pipette recordings from the M-dominant cones, the success rate in obtaining cone responses from a retinal slice was $\sim 100 \%$ and the average amplitudes of the saturating responses were similar in WT and $G n b 3^{-1-}$ mice. The latter observation suggests that the number of functional cGMP-gated channels is unaffected by the absence of $\mathrm{G} \beta 3$ and is consistent with the immunocytochemical and Western blot measurements showing normal levels of the channel subunits.

These results are consistent with studies showing that deletion of $\mathrm{G} \gamma 1$ reduces sensitivity, but does not eliminate rod transduction (Lobanova et al., 2008; Kolesnikov et al., 2011).
However, these studies interpreted the role of $\mathrm{G} \beta \gamma$ differently: Lobanova et al. (2008) attributed the reduction in the response parameters mainly to the lower level of $\mathrm{G} \alpha \mathrm{t} 1$, thus suggesting an indirect role for $G \beta \gamma$, whereas Kolesnikov et al. (2011) concluded that $G \beta \gamma$ has a direct role in increasing the efficiency of activation of $\mathrm{G} \alpha \mathrm{t}$ l by photoactivated rhodopsin in rods. Our results suggest that the efficiency by which photoactivated cone opsin activates $\mathrm{G} \alpha \mathrm{t} 2$ is not compromised by the lack of $\mathrm{G} \beta 3$. This is because the reduction in amplification and sensitivity were similar to the average decrease in $\mathrm{G} \alpha \mathrm{t} 2$ concentration in the cone outer segments. An important question is whether the transduction cascade in the absence of $G \beta 3$ was carried on by the monomeric $\mathrm{G} \alpha$, or by a different isoform of $\mathrm{G} \beta$ that compensated for the loss of the deleted subunit. The involvement of the divergent $\beta$ subunit, G $\beta 5$, can be ruled out as in vivo studies show that $\mathrm{G} \beta 5$ forms a complex with R7 RGS proteins and not with any $\mathrm{G} \gamma$ subunits (reviewed by Simonds and Zhang, 2000; Witherow et al., 2000; Blake et al., 2001). As for $\mathrm{G} \beta 4$, this subunit is not expressed in WT cones (Siegert et al., 2012), and because the transcript is not upregulated in the knock-out, this subunit is unlikely to be involved. At this point our results do not rule out a contribution by a small amount of $\mathrm{G} \beta 2$ whose transcript is present in cones and was undetectable by our antibody, or $\mathrm{G} \beta 1$ whose transcript is absent but may be upregulated in the $\mathrm{Gnb3}^{-1-}$ cones. However, because it has been shown in in vitro experiments that $\mathrm{G} \alpha \mathrm{t} 1$ could be activated by excited rhodopsin in the absence of $\mathrm{G} \beta \gamma$ (Phillips et al., 1992; Herrmann et al., 2006), we believe that monomeric $\mathrm{G} \alpha$ can transduce the light signal. Alternatively, it may be possible that $\mathrm{G} \gamma$ on its own could assume the function of the G $\beta \gamma$ dimer.

\section{$\mathrm{G} \beta 3$ deletion does not affect inactivation of the transduction cascade}

The similarity in the time to peak and nearly identical shape of the dim flash responses observed for all three genotypes strongly suggest that the inactivation of the cone transduction cascade was unaffected by deleting $G \beta 3$. The slopes of the average recovery duration versus logarithm of flash intensity $\left(\tau_{\mathrm{s}}\right)$ were also similar. Furthermore, all recovery data points fell on the same trajectory after shifting $\mathrm{Gnb3}^{+/-}$and Gnb3 $3^{-1-}$ data $2 \times$ and $8 \times$ to the left correspondingly along the intensity axis. This shows that the same recovery times as in WT cones were achieved in $\mathrm{Gnb3}^{+/-}$and $\mathrm{Gnb3}^{-1-}$ cones at $2 \times$ and $8 \times$ brighter flashes. The absence of a recovery phenotype in $\mathrm{Gnb3}^{-I-}$ cones implies that the interaction of the G $\alpha \mathrm{t} 2$-PDE6 complex with RGS9 proceeds normally in the absence of $\mathrm{G} \beta \gamma$. We hypothesize that the main reason for the above shift is decreased numbers of activated $\mathrm{G} \alpha \mathrm{t} 2$ subunits per photoisomerization in the $G n b 3^{-1-}$ cones. Our finding in cones contrasts with the finding that deletion of $\mathrm{G} \gamma 1$ in rods accelerates response recovery (Kolesnikov et al., 2011). This difference may be because of an indirect effect of $G \beta \gamma$ on other cascade elements in rods but not in cones (such as PDE $\gamma$ ), or perhaps it may mean that deletion of $\mathrm{G} \beta$ could have different effects than deletion of $\mathrm{G} \gamma$.

\section{References}

Blake BL, Wing MR, Zhou JY, Lei Q, Hillmann JR, Behe CI, Morris RA, Harden TK, Bayliss DA, Miller RJ, Siderovski DP (2001) G beta association and effector interaction selectivities of the divergent $\mathrm{G}$ gamma subunit G gamma(13). J Biol Chem 276:49267-49274. CrossRef Medline

Brockerhoff SE, Rieke F, Matthews HR, Taylor MR, Kennedy B, Ankoudinova I, Niemi GA, Tucker CL, Xiao M, Cilluffo MC, Fain GL, Hurley JB (2003) 
Light stimulates a transducin-independent increase of cytoplasmic $\mathrm{Ca}^{2+}$ and suppression of current in cones from the zebrafish mutant nof. J Neurosci 23:470-480. Medline

Burns ME, Pugh EN Jr (2010) Lessons from photoreceptors: turning off g-protein signaling in living cells. Physiology (Bethesda) 25:72-84. CrossRef Medline

Calvert PD, Krasnoperova NV, Lyubarsky AL, Isayama T, Nicoló M, Kosaras B, Wong G, Gannon KS, Margolskee RF, Sidman RL, Pugh EN Jr, Makino CL, Lem J (2000) Phototransduction in transgenic mice after targeted deletion of the rod transducin alpha-subunit. Proc Natl Acad Sci U S A 97:13913-13918. CrossRef Medline

Chang B, Dacey MS, Hawes NL, Hitchcock PF, Milam AH, Atmaca-Sonmez P, Nusinowitz S, Heckenlively JR (2006) Cone photoreceptor function loss-3, a novel mouse model of achromatopsia due to a mutation in Gnat2. Invest Ophthalmol Vis Sci 47:5017-5021. CrossRef Medline

Chen CK, Woodruff ML, Chen FS, Shim H, Cilluffo MC, Fain GL (2010) Replacing the rod with the cone transducin subunit decreases sensitivity and accelerates response decay. J Physiol 588:3231-3241. CrossRef Medline

Daniele LL, Insinna C, Chance R, Wang J, Nikonov SS, Pugh EN Jr (2011) A mouse $\mathrm{M}$-opsin monochromat: retinal cone photoreceptors have increased M-opsin expression when S-opsin is knocked out. Vision Res 51:447-458. CrossRef Medline

Deng WT, Sakurai K, Liu J, Dinculescu A, Li J, Pang J, Min SH, Chiodo VA, Boye SL, Chang B, Kefalov VJ, Hauswirth WW (2009) Functional interchangeability of rod and cone transducin alpha-subunits. Proc Natl Acad Sci U S A 106:17681-17686. CrossRef Medline

Dhingra A, Sulaiman P, Xu Y, Fina ME, Veh RW, Vardi N (2008) Probing neurochemical structure and function of retinal ON bipolar cells with a transgenic mouse. J Comp Neurol 510:484-496. CrossRef Medline

Dhingra A, Ramakrishnan H, Neinstein A, Fina ME, Xu Y, Li J, Chung DC, Lyubarsky A, Vardi N (2012) G $\beta 3$ is required for normal light on responses and synaptic maintenance. J Neurosci 32:11343-11355. CrossRef Medline

Ding XQ, Fitzgerald JB, Matveev AV, McClellan ME, Elliott MH (2008) Functional activity of photoreceptor cyclic nucleotide-gated channels is dependent on the integrity of cholesterol- and sphingolipid-enriched membrane domains. Biochemistry 47:3677-3687. CrossRef Medline

Dolph PJ, Man-Son-Hing H, Yarfitz S, Colley NJ, Deer JR, Spencer M, Hurley JB, Zuker CS (1994) An eye-specific G beta subunit essential for termination of the phototransduction cascade. Nature 370:59-61. CrossRef Medline

Evanko DS, Thiyagarajan MM, Wedegaertner PB (2000) Interaction with Gbetagamma is required for membrane targeting and palmitoylation of Galpha(s) and Galpha(q). J Biol Chem 275:1327-1336. CrossRef Medline

Fung BK, Lieberman BS, Lee RH (1992) A third form of the G-protein beta subunit: 2. Purification and biochemical properties. J Biol Chem 267: 24782-24788. Medline

Gopalakrishna KN, Boyd KK, Artemyev NO (2012) Comparative analysis of cone and rod transducins using chimeric Galpha subunits. Biochemistry 51:1617-1624. CrossRef Medline

Herrmann R, Heck M, Henklein P, Hofmann KP, Ernst OP (2006) Signal transfer from GPCRs to $\mathrm{G}$ proteins: role of the $\mathrm{G}$ alpha $\mathrm{N}$-terminal region in rhodopsin-transducin coupling. J Biol Chem 281:30234-30241. CrossRef Medline

Hu G, Zhang Z, Wensel TG (2003) Activation of RGS9-1GTPase acceleration by its membrane anchor, R9AP. J Biol Chem 278:14550-14554. CrossRef Medline

Huang L, Max M, Margolskee RF, Su H, Masland RH, Euler T (2003) G protein subunit $\mathrm{G}$ gamma 13 is coexpressed with $\mathrm{G}$ alpha $\mathrm{o}$, $\mathrm{G}$ beta 3 , and $\mathrm{G}$ beta 4 in retinal ON bipolar cells. J Comp Neurol 455:1-10. CrossRef Medline

Kolesnikov AV, Rikimaru L, Hennig AK, Lukasiewicz PD, Fliesler SJ, Govardovskii VI, Kefalov VJ, Kisselev OG (2011) G-protein $\beta \gamma$-complex is crucial for efficient signal amplification in vision. J Neurosci 31:80678077. CrossRef Medline

Krispel CM, Chen D, Melling N, Chen YJ, Martemyanov KA, Quillinan N, Arshavsky VY, Wensel TG, Chen CK, Burns ME (2006) RGS expression rate-limits recovery of rod photoresponses. Neuron 51:409-416. CrossRef Medline

Lamb TD, Pugh EN Jr (1992) A quantitative account of the activation steps involved in phototransduction in amphibian photoreceptors. J Physiol 449:719-758. Medline

Larhammar D, Nordström K, Larsson TA (2009) Evolution of vertebrate rod and cone phototransduction genes. Philos Trans R Soc Lond B Biol Sci 364:2867-2880. CrossRef Medline

Lee RH, Lieberman BS, Yamane HK, Bok D, Fung BK (1992) A third form of the $G$ protein beta subunit: 1 . Immunochemical identification and localization to cone photoreceptors. J Biol Chem 267:24776-24781. Medline

Lerea CL, Somers DE, Hurley JB, Klock IB, Bunt-Milam AH (1986) Identification of specific transducin alpha subunits in retinal rod and cone photoreceptors. Science 234:77-80. CrossRef Medline

Lobanova ES, Finkelstein S, Herrmann R, Chen YM, Kessler C, Michaud NA, Trieu LH, Strissel KJ, Burns ME, Arshavsky VY (2008) Transducin $\gamma$-subunit sets expression levels of $\alpha$ - and $\beta$-subunits and is crucial for rod viability. J Neurosci 28:3510-3520. CrossRef Medline

Lobanova ES, Herrmann R, Finkelstein S, Reidel B, Skiba NP, Deng WT, Jo R, Weiss ER, Hauswirth WW, Arshavsky VY (2010) Mechanistic basis for the failure of cone transducin to translocate: why cones are never blinded by light. J Neurosci 30:6815-6824. CrossRef Medline

Lyubarsky AL, Falsini B, Pennesi ME, Valentini P, Pugh EN Jr (1999) UVand midwave-sensitive cone-driven retinal responses of the mouse: a possible phenotype for coexpression of cone photopigments. J Neurosci 19: 442-455. Medline

Lyubarsky AL, Chen C, Simon MI, Pugh EN Jr (2000) Mice lacking G-protein receptor kinase 1 have profoundly slowed recovery of conedriven retinal responses. J Neurosci 20:2209-2217. Medline

Lyubarsky AL, Lem J, Chen J, Falsini B, Iannaccone A, Pugh EN Jr (2002) Functionally rodless mice: transgenic models for the investigation of cone function in retinal disease and therapy. Vision Res 42:401-415. CrossRef Medline

Marrari Y, Crouthamel M, Irannejad R, Wedegaertner PB (2007) Assembly and trafficking of heterotrimeric $\mathrm{G}$ proteins. Biochemistry 46:7665-7677. CrossRef Medline

Martemyanov KA, Arshavsky VY (2009) Biology and functions of the RGS9 isoforms. Prog Mol Biol Transl Sci 86:205-227. CrossRef Medline

Matveev AV, Quiambao AB, Browning Fitzgerald J, Ding XQ (2008) Native cone photoreceptor cyclic nucleotide-gated channel is a heterotetrameric complex comprising both CNGA3 and CNGB3: a study using the conedominant retina of $\mathrm{Nrl}^{-1-}$ mice. J Neurochem 106:2042-2055. CrossRef Medline

Michalakis S, Geiger H, Haverkamp S, Hofmann F, Gerstner A, Biel M (2005) Impaired opsin targeting and cone photoreceptor migration in the retina of mice lacking the cyclic nucleotide-gated channel CNGA3. Invest Ophthalmol Vis Sci 46:1516-1524. CrossRef Medline

Montiani-Ferreira F, Fischer A, Cernuda-Cernuda R, Kiupel M, DeGrip WJ, Sherry D, Cho SS, Shaw GC, Evans MG, Hocking PM, Petersen-Jones SM (2005) Detailed histopathologic characterization of the retinopathy, globe enlarged (rge) chick phenotype. Mol Vis 11:11-27. Medline

Montiani-Ferreira F, Shaw GC, Geller AM, Petersen-Jones SM (2007) Electroretinographic features of the retinopathy, globe enlarged (rge) chick phenotype. Mol Vis 13:553-565. Medline

Morgan JL, Dhingra A, Vardi N, Wong RO (2006) Axons and dendrites originate from neuroepithelial-like processes of retinal bipolar cells. Nat Neurosci 9:85-92. CrossRef Medline

Ng L, Lyubarsky A, Nikonov SS, Ma M, Srinivas M, Kefas B, St Germain DL, Hernandez A, Pugh EN Jr, Forrest D (2010) Type 3 deiodinase, a thyroid-hormone-inactivating enzyme, controls survival and maturation of cone photoreceptors. J Neurosci 30:3347-3357. CrossRef Medline

Nikonov S, Engheta N, Pugh EN Jr (1998) Kinetics of recovery of the darkadapted salamander rod photoresponse. J Gen Physiol 111:7-37. CrossRef Medline

Nikonov SS, Daniele LL, Zhu X, Craft CM, Swaroop A, Pugh EN Jr (2005) Photoreceptors of $\mathrm{Nrl}^{-1-}$ mice coexpress functional S- and M-cone opsins having distinct inactivation mechanisms. J Gen Physiol 125:287304. CrossRef Medline

Nikonov SS, Kholodenko R, Lem J, Pugh EN Jr (2006) Physiological features of the $\mathrm{S}$ - and $\mathrm{M}$-cone photoreceptors of wild-type mice from singlecell recordings. J Gen Physiol 127:359-374. CrossRef Medline

Nikonov SS, Brown BM, Davis JA, Zuniga FI, Bragin A, Pugh EN Jr, Craft CM (2008) Mouse cones require an arrestin for normal inactivation of phototransduction. Neuron 59:462-474. CrossRef Medline

Ong OC, Yamane HK, Phan KB, Fong HK, Bok D, Lee RH, Fung BK (1995) 
Molecular cloning and characterization of the $G$ protein gamma subunit of cone photoreceptors. J Biol Chem 270:8495-8500. CrossRef Medline

Peng YW, Robishaw JD, Levine MA, Yau KW (1992) Retinal rods and cones have distinct G-protein beta and gamma subunits. Proc Natl Acad Sci U S A 89:10882-10886. CrossRef Medline

Pepperberg DR, Cornwall MC, Kahlert M, Hofmann KP, Jin J, Jones GJ, Ripps H (1992) Light-dependent delay in the falling phase of the retinal rod photoresponse. Vis Neurosci 8:9-18. CrossRef Medline

Phillips WJ, Wong SC, Cerione RA (1992) Rhodopsin/transducin interactions. II. Influence of the transducin-beta gamma subunit complex on the coupling of the transducin-alpha subunit to rhodopsin. J Biol Chem 267: 17040-17046. Medline

Ritchey ER, Bongini RE, Code KA, Zelinka C, Petersen-Jones S, Fischer AJ (2010) The pattern of expression of guanine nucleotide-binding protein beta 3 in the retina is conserved across vertebrate species. Neuroscience 169:1376-1391. CrossRef Medline

Ritchey ER, Zelinka C, Tang J, Liu J, Code KA, Petersen-Jones S, Fischer AJ (2012) Vision-guided ocular growth in a mutant chicken model with diminished visual acuity. Exp Eye Res 102:59-69. CrossRef Medline

Schwindinger WF, Giger KE, Betz KS, Stauffer AM, Sunderlin EM, SimSelley LJ, Selley DE, Bronson SK, Robishaw JD (2004) Mice with deficiency of G-protein gamma3 are lean and have seizures. Mol Cell Biol 24:7758-7768. CrossRef Medline

Siegert S, Cabuy E, Scherf BG, Kohler H, Panda S, Le YZ, Fehling HJ, Gaidatzis
D, Stadler MB, Roska B (2012) Transcriptional code and disease map for adult retinal cell types. Nat Neurosci 15:487- 495:S1-S2. CrossRef Medline

Simonds WF, Zhang JH (2000) New dimensions in G-protein signalling: G beta 5 and the RGS proteins. Pharm Acta Helv 74:333-336. CrossRef Medline

Slepak VZ (2009) Structure, function, and localization of Gbeta5-RGS complexes. Prog Mol Biol Transl Sci 86:157-203. CrossRef Medline

Tummala H, Ali M, Getty P, Hocking PM, Burt DW, Inglehearn CF, Lester DH (2006) Mutation in the guanine nucleotide-binding protein beta-3 causes retinal degeneration and embryonic mortality in chickens. Invest Ophthalmol Vis Sci 47:4714-4718. CrossRef Medline

Witherow DS, Wang Q, Levay K, Cabrera JL, Chen J, Willars GB, Slepak VZ (2000) Complexes of the G-protein subunit gbeta 5 with the regulators of G-protein signaling RGS7 and RGS9: characterization in native tissues and in transfected cells. J Biol Chem 275:2487224880. CrossRef Medline

Xu J, Morris L, Fliesler SJ, Sherry DM, Ding XQ (2011) Early-onset, slow progression of cone photoreceptor dysfunction and degeneration in CNG channel subunit CNGB3 deficiency. Invest Ophthalmol Vis Sci 52:3557-3566. CrossRef Medline

Xu Y, Dhingra A, Fina ME, Koike C, Furukawa T, Vardi N (2012) mGluR6 deletion renders the TRPM1 channel in retina inactive. J Neurophysiol 107:948-957. CrossRef Medline 